\title{
ESPECTÁCULOS PARATEATRALES EN BADAJOZ EN EL SIGLO XIX (HASTA 1886)
}

\author{
Ángel Suárez Muñoz \\ Universidad de Extremadura
}

Sergio Suárez Ramírez

\section{INTRODUCCIÓN}

En sendos artículos ${ }^{1}$, publicados en la Revista de Estudios Extremeños, tuvimos la oportunidad de aportar datos que confirmaban la enorme presencia e importancia social del teatro durante el siglo XIX en la ciudad de Badajoz y en toda la comunidad autónoma, en correspondencia con la que se registraba en el conjunto del país y, en general, en toda la Península Ibérica.

Realizados aquellos primeros apuntes, nos permitimos retomar la idea con la que se abría el segundo de los artículos mencionados:

1 Suárez MuÑoz, Ángel: «El teatro en la ciudad de Badajoz en el siglo XIX. Los comienzos.» Revista de Estudios Extremeños (1996), tomo LII, núm. I y «El teatro extremeño en el tránsito del siglo XIX al XX.» Revista de Estudios Extremeños (1998), tomo LIV, núm. I. 
Durante el siglo XIX el Teatro adquiere una dimensión social, convirtiéndose en la principal actividad capaz de reunir a grupos sociales diversos en torno a un mismo espectáculo. En un proceso continuo y cada vez más extendido, llega a todos los rincones e implica a ricos y a pobres.

El Teatro no sólo representa una actividad a la que se asiste sin más; se participa a través de grupos de aficionados y personas de ocupaciones dispares escriben obras imitando los géneros que más demanda tienen ${ }^{2}$.

Resaltando el carácter de espectáculo atribuido al teatro del siglo XIX, quisiéramos en esta ocasión llamar la atención sobre lo que se ha dado en llamar parateatro. Para situar perfectamente este término es preciso tener en cuenta que lo que conocemos como teatro presenta unas características surgidas de la integración de todos los elementos que lo forman en lo que se denomina representación. Por esta razón nos encontramos con múltiples actividades en la vida de las personas, basadas en el arte de representar, que pueden considerarse relacionadas con el teatro. En este sentido, José M. ․ Díez Borque ${ }^{3}$ comenta:

... es el caso que hay espectáculos basados en la representación, con argumento (musicales, mimo, marionetas, ballet), a veces en la órbita de lo teatral. Pero hay otros apoyados en una especial capacitación y potenciación de habilidades del actuante: circo, toros, deportes, que coinciden con el teatro en que se actúa, se hace algo para que los demás lo vean y/u oigan, aunque las diferencias sean de esencia, de modo que pueden estudiarse aislada o independientemente. Pero todo se complica al internarnos en los terrenos de la fiesta, el rito, el mito visualizado, en los que puede darse una participación lúdica, profundamente inversora, o motivada e impuesta por altos ideales (procesiones y ceremonias), e incluso puede producirse la pura y simple contemplación, aunque las razones sean distintas. Hay una variada escala, de la confusión a la perfecta delimitación de teatro y fiesta, con una rica pluralidad de posibilidades intermedias.

De esta aproximación entre teatro y fiesta nos habla también Francisco Rodríguez Adrados ${ }^{4}$ cuando escribe:

Ha podido verse que en las fiestas pueden aislarse unidades elementales que coinciden en líneas generales con las que previamente hemos aislado en el Tea-

2 Ibídem, p. 65.

3 Díz BoRQue, José M.. (1988), Historia del Teatro en España, II. Madrid: Taurus, p. 49. Cf. además el apartado V.2.7. («Diversiones populares y parateatro») del artículo de José Romera Castillo, «Una bibliografía (selecta) para la reconstrucción de la vida escénica española en la segunda mitad del siglo XIX», Signa 9 (2000), pp. 259-421 (pp. 315-322 para el apartado señalado).

4 Rodríguez Adrados, Francisco (1972), Fiesta, comedia y tragedia. Sobre los orígenes griegos del teatro. Barcelona: Planeta, p. 52. 
tro... el Teatro representa una selección de diversos momentos de la Fiesta, una organización de los mismos, una presentación mitificada mimética y verbalizada».

En definitiva, el parateatro viene a estar muy cerca de lo que es una segunda teatralidad, ya que la unidad primaria de la teatralidad está constituida por el mimema, término reservado para lo fundamentalmente teatral y que el profesor Sito Alba ${ }^{5}$ define como:

La unidad de teatralidad esencial, primaria y, en cierto modo, mínima que realiza una función determinada, pudiendo ésta ser variable en las distintas utilizaciones posibles. Se emplea el término teatralidad, ya que el mimema puede aparecer en el teatro - generalmente unido a otros, constituye la obra teatralpero también se encuentra en la vida cotidiana, en los ritos, en los mitos, en distintos géneros literarios, etc. Es unidad esencial porque sin él no hay teatralidad. Primaria porque puede desarrollarse y asociarse a otras. Y mínima porque si se puede dividir, se trata no de un mimema, sino de varios, y porque no acepta, cuando se ha reducido a su verdadero ser, que se le quite ningún elemento, ya que quedaría o desprovisto de sentido teatral o incompleto sin cumplir la función prevista.

Esos elementos o componentes esenciales del mimema son seis, según Sito Alba: 1. el autor o director, 2. el texto literario y los códigos complementarios, 3. el actor o personaje, 4. el espacio, 5. el tiempo y 6. el público. Como podremos comprobar a lo largo de este artículo, los espectáculos parateatrales reúnen todos o casi todos los elementos del mimema, pero constituyen esa segunda teatralidad por su mayor relación con lo festivo y porque suele carecer de texto.

De sobra es conocido que el término español «teatro» y sus equivalentes en los demás idiomas de Occidente, proviene del vocablo latino «theatrum», que a su vez es un derivado de la palabra griega Jeatron, formada del verbo Jeaomai, que significa mirar. En los diccionarios actuales, con ligeras variantes, se define la palabra siguiendo al de la Real Academia, que da las siguientes acepciones:

TEATRO: Edificio o sitio destinado a la representación de obras dramáticas o a otros espectáculos públicos propios de la escena./ Sitio o lugar en que se ejecuta una cosa a vista de numeroso concurso./ Escenario o escena./ Práctica en el arte de representar comedias. Ese actor tiene mucho TEATRO./ Conjunto de todas las producciones dramáticas de un pueblo, de una época o de un autor. El TEATRO

5 Sito Alba, Manuel (1987), Análisis de la semiótica teatral. Madrid: UNED, p. 33. 
griego; el TEATRO del siglo XVII; el TEATRO de Calderón./ Profesión de actor. Dedicarse al TEATRO./ Arte de componer obras dramáticas o de representarlas. Este escritor o ese actor conocen mucho el TEATRO./ Literatura dramática. Lope de Rueda fue uno de los fundadores del TEATRO en España./ Lugar en que ocurren acontecimientos notables y dignos de atención. El TEATRO de la guerra.l Lugar donde una cosa está expuesta a la estimación o censura de las gentes./ Conjunto de espectadores que están viendo una representación teatral ${ }^{6}$.

En casi todos los diccionarios se insiste en las primeras acepciones: Teatro es, ante todo, edificio o un sitio o lugar. No obstante, volviendo a la etimología, el verdadero sentido del vocablo que se refiere a esos emplazamientos se asocia al destino a que se dedican, o el tipo de acción que en ellos se ejecuta: representación de obras dramáticas, ejecución de una cosa a vista de numeroso concurso, producción de acontecimientos notables y dignos de atención, exposición de una cosa a la estimación o censura de las gentes.

En este sentido teatro y parateatro caminan de la mano. También en las funciones parateatrales hay representación, se ejecutan cosas a la vista de numeroso público, expuestas a su estimación y censura. Si hemos de establecer una diferenciación nos quedamos con las palabras de Díez Borque ${ }^{7}$ :

\footnotetext{
Dejando aparte los espectáculos basados en la representación, argumentales o no, y en la visualización de una actividad, puede decirse que en el parateatro, en la fiesta, aunque aparezcan, se alteran la función y sentido de los elementos que integran el hecho teatral. El texto pierde importancia, o incluso desaparece, con lo que cambian los valores literarios, ideológicos, estéticos que el teatro posee como manifestación literaria que también es.
}

\section{MANIFESTACIONES PARATEATRALES EN BADAJOZ EN EL S. XIX}

Es opinión generalizada entre los especialistas que han estudiado el teatro y las funciones parateatrales del siglo XIX señalar la dificultad que existe a la hora de marcar el comienzo y el final de lo teatral, dificultad más acentuada cuando dicha actividad teatral es tan intensa y variada. Se nos recuerda inmediatamente que los teatros fueron utilizados para bailes, actos políticos, galas, funciones literarias, etc. con lo que de teatral tienen éstas y otras celebraciones. En general, todo aquello que suponía una ruptura con la rutina dia-

6 Diccionario manual e ilustrado de la Lengua Española, Madrid: Real Academia Española, 1985, p. 2147.

7 Ibidem, p. 52. 
ria, alcanzó en este siglo el carácter de espectáculo, debido principalmente a que era capaz de congregar a su alrededor un público deseoso de dejar escapar su imaginación, evadiéndose así de las penurias que conformaban su día a día. Vista la rentabilidad del teatro, convertido en una industria, los empresarios se esmeraron y rivalizaron entre ellos en ofrecer espectáculos que fueran capaces de saciar la curiosidad y el interés del público.

Este panorama teatral que llena por completo todo el siglo XIX, tiene en Badajoz una fecha y un acontecimiento que le marca y condiciona. La fecha el 30 de octubre de 1886; el acontecimiento, la inauguración del Teatro López de Ayala. Este día y lo que sucedió marcan un antes y un después en la vida social de los habitantes de esta ciudad, porque, como hemos comentado, el teatro y los espectáculos que se montan en su entorno condicionan y organizan la vida cultural y de relaciones de nuestra ciudad. Además, si también en este terreno Badajoz ha ido rezagada con respecto al ritmo seguido por otras ciudades de su categoría, en los últimos diez años del siglo acelerará y experimentará una evolución positiva en todos los terrenos.

A continuación vamos a dar cuenta de los espectáculos parateatrales celebrados en Badajoz en ese periodo que hemos denominado «el antes», o sea, en los años previos a la inauguración del Teatro López de Ayala. Hemos agrupado los espectáculos en cinco apartados, teniendo en cuenta el parecido o proximidad entre ellos, sin que eso impida otra clasificación distinta.

\section{a) Espectáculos ecuestres}

Los primeros testimonios los encontramos en septiembre de 1862. En concreto el viernes día 19 tuvo lugar en la plaza de San Juan una función muy animada en la que se ejecutaron suertes sorprendentes, tanto en los caballos como en la maroma, llamando particularmente la atención la subida y bajada del Sr. Casali. Para el domingo día 21 se anunció una nueva función del mismo Sr. Casali en la que ejecutaría el número titulado El triunfo de la bandera, que consistía en la subida de cinco aldeanos por dos cuerdas paralelas desde el piso de la plaza hasta por encima de los palcos. Para el domingo día 28 se anunció una nueva función de las actrices y actores de la Compañía Ecuestre, una vez recuperados de sus dolencias, ejecutando nuevos y sorprendentes ejercicios.

Ya anotamos, en los estudios referidos al principio, que la plaza de San Juan o Campo de San Juan albergó durante todo el siglo XIX el primer y único teatro conocido, hasta el año 1886 en que se inaugura, unos metros más abajo, en la plaza de Minayo, el denominado López de Ayala. Este teatro del 
Campo de San Juan, antiguo Hospital de la Piedad, arranca justamente desde 1800 , cuando Jaime Carlés y Busquets lo compra al amparo de la Real Cédula de 25 de septiembre de 1798 que regula la compra-venta de bienes raíces pertenecientes a Hospitales, Hospicios, Casas de Misericordia o de Reclusión, una de las consecuencias derivadas de la desamortización emprendida por Mendizábal.

La plaza de San Juan era por esa época «el punto de reunión más notable de la ciudad», tal y como lo calificaba Pascual Madoz ${ }^{8}$. No es de extrañar por tanto que se elija este lugar para celebrar los espectáculos públicos que atraen a la ciudadanía. Nótese, para lo que venimos exponiendo, el hecho de organizarse ante las puertas del teatro que entonces funcionaba en la localidad.

Los espectáculos ecuestres debieron despertar en los ciudadanos de Badajoz una gran expectación a tenor del número de funciones de esta clase que se repetirá en los años siguientes. Recordemos que, a nivel nacional, existía una curiosa puja entre el teatro y el circo. Fueron los circos de Paul y Price los principales impulsores de espectáculos desconocidos hasta entonces, entre los que se encontraban los que la crítica denominó «literatura gimnástica y caballar». Hay constancia documental de que hasta 1852 las solicitudes para construir escenarios dentro de los circos para dar espectáculos mixtos seguían siendo denegadas. Con el tiempo y el empuje del liberalismo se fueron desterrando esos prejuicios, lo que propició la construcción de edificios mixtos, como el de Parish o el Colón, que indistintamente daban espectáculos de uno u otro tipo.

En nuestra ciudad, dado que los documentos encontrados nos sitúan ya por encima de la fecha señalada anteriormente, asistiremos a espectáculos circenses dentro del propio teatro, invirtiéndose en el tipo de edificio que, como hemos comentado, se puso de moda. A ello obligó el que Badajoz careciese de espacios donde ubicar los acontecimientos públicos, disponiéndose únicamente del teatro del Campo de San Juan. Así, según el tiempo meteorológico imperante, se escogía uno u otro espacio, esto es, el interior del teatro o la calle.

La compañía del circo Price llegó también a Badajoz. El domingo día 22 de marzo de 1863 tuvo lugar en la ciudad una sorprendente función ecuestre a cargo de una parte de la numerosa compañía de Mr. Tomas Price. Se ejecutaron grandes y difíciles ejercicios, concluyendo con la presentación de dos enormes elefantes. Aunque en esta ocasión no se nos dice dónde se verificó

8 MADOZ, Pascual (1953), Diccionario histórico-geográfico de Extremadura, I. Cáceres: Departamento de Seminarios de la Jefatura Provincial del Movimiento. 
la función, deducimos, por la época y por la magnitud de los animales exhibidos, que debió ser nuevamente en la calle, probablemente en la misma Plaza de San Juan.

Hasta diez años después no volvemos a tener noticias de un espectáculo ecuestre. Nuevamente es la compañía de Mr. Price la que lo protagoniza. En el mes de febrero, durante los tres días de Carnaval, la Compañía ecuestre y gimnástica dio sendas funciones esta vez en el interior del teatro. La señora Gaetner destacó en los ejercicios de equitación, los Leoni estuvieron admirables en los trabajos que ejecutaron en los trapecios, los hermanos Gaetner Kennebel hicieron las delicias del público; por último la señorita Codona, su hermano, los clowns y demás artistas cumplieron con su cometido.

Un nuevo espacio se va a ofertar para la celebración de estos espectáculos, la plaza de toros. A ello contribuye, sin duda, el carácter cada vez más reglado y serio que han ido alcanzado estas funciones. Es mucho el aparato escenográfico que se requiere, también es mucha la seguridad que se exige para lo que es fundamental la ubicación del público y, cómo no, la rentabilidad económica también ejerce su influencia. Hay que controlar el número de asistentes y evitar en lo posible la presencia de espectadores «gorrones» que se acercan a mirar, pero no pagan la entrada correspondiente. Con un recinto cerrado como el coso taurino todas estas contingencias quedan cubiertas.

Por eso, no extraña que en la tarde del viernes día 18 de septiembre de 1874 diera la primera función de las inicialmente previstas en la plaza de toros la Compañía gimnástica y ecuestre dirigida por Mr. Ferroni. Los trabajos anunciados se realizaron con perfección por todos los que tomaron parte, especialmente la joven Miss Ella, que ejecutó los suyos con agilidad. Los años han pasado y la feria de septiembre que por entonces se celebraba en Badajoz era pretexto para el lucimiento de los nuevos avances y progresos realizados por las compañías. De ahí que en algunas ocasiones, aunque no siempre, se contara con una carpa circense, que, lógicamente, se situaba en el centro de la población y lo más próximo posible al teatro, lugar que era asociado por los habitantes de la ciudad con la idea de espectáculo o diversión. Ésa es la razón de que para la noche del domingo día 20 se anunciara una variada función en el circo situado en la plaza de Minayo.

El hecho de reservar el edificio del teatro para espectáculos más propios del arte escénico hace que la plaza de toros de la ciudad se vaya asociando a los acontecimientos más relacionados con el circo. En 1878, concretamente el domingo día 17 de febrero, se celebró en la plaza de toros la primera función dada por la compañía ecuestre y gimnástica, dirigida por Enrique Díaz. Los ejercicios que se expusieron fueron: las amazonas sobre los caballos; los caballos amaestrados por Enrique Díaz y el burro sabio Rigoletto. También 
actuó la familia Martini. El viernes día 22 volvió a actuar en la plaza de toros esta misma compañía en función dedicada a la sociedad de Badajoz. Los gimnastas alemanes de la familia Martini realizaron la «percha musical»; la niña trabajó en el trapecio. Actuaron también los nuevos clowns Mirantony, Alfredo y Romay. El niño Kenebel realizó unos juegos de malabares. Para el domingo día 24 se anunció otra función más en la que el director de la compañía, Enrique Díaz, haría sus ejercicios con un caballo en pelo.

Llamamos la atención de los lectores acerca de la originalidad en la denominación de los números que componían las funciones. Nada hemos podido averiguar que nos permita describir con exactitud en qué consistían. Hemos de dejarlo todo en manos de la imaginación, más o menos generosa en cada uno de nosotros.

Las compañías ecuestres, como el resto de compañías profesionales que recorrían el territorio nacional, fueran de la índole que fueran, solían denominarse de maneras muy diversas, aunque se dedicaran a lo mismo. Observemos si no cómo se autodenomina la compañía que visitó Badajoz unos días después. Concretamente el domingo día 31 de marzo tuvo lugar en la Plaza de Toros una función a cargo de la compañía ecuestre y zoológica (el destacado es nuestro) que dirigían los señores Onra, Mayols y Edmons. Los ejercicios ecuestres fueron realizados por las señoritas Mayols y Elena y míster Onra y su hijo. En la barra fija y en el trapecio actuaron míster Mayols y el joven Ayala. Además de los clowns participaron míster Emilio en los juegos malabares, el niño Carter sobre un caballo en pelo y los elefantes amaestrados que presentó míster Edmons. Días después, la compañía ecuestre y zoológica volvió a dar una función en la plaza de toros, el jueves día 4 de abril.

Pero, sin duda, fue la compañía de Enrique Díaz la que mejor acogida tuvo en nuestra ciudad. Al menos eso se desprende de las reiteradas visitas que nos hacía. En sus idas y venidas al vecino Portugal, esta compañía ecuestre paraba en Badajoz para recuperarse económicamente, consciente como era de los favores que el público le dispensaba. Una de las estancias más prolongadas se documenta en la primavera de 1880. El domingo día 11 de abril dio la primera función en la plaza de toros la compañía ecuestre y gimnástica dirigida por Enrique Díaz. En ella, tras algunos ejercicios ecuestres a cargo de las amazonas, se presentaron el señor Díaz con cuatro caballos amaestrados, el joven Eduardo Díaz, los clowns, especialmente Toni Grice, la familia Colmar y Mis Zuid. La segunda función se verificó el jueves día 15 en el mismo escenario. En esta ocasión destacaron la señorita Díaz que hizo de torera y el joven Eduardo Díaz que realizó diversos ejercicios a caballo, solo y en unión de su hermano, el director de la compañía. Los saltos fueron realizados por Pepino; Boby hizo equilibrios. También participaron Tony Grice 
y Lurel (sic) y su pequeño hijo en el velocípedo aéreo. La tercera se celebró el domingo día 18. Intervinieron míster Boby, míster Toni, Enrique Díaz en Treinta días o la vida de un jugador, título que recuerda el del drama trágico con tres actos y en prosa traducido por José Ulanga Alcocín y representado en el teatro del Campo de San Juan el 2 de febrero de 1868, por la Compañía dirigida por Domingo López Ayllón, Treinta años y la vida de un jugador. La familia Mariani, la amazona señorita Díaz, la familia Colmar en los anillos volantes también actuaron en la función de ese día.

La respuesta que daba el público de nuestra ciudad a estas actuaciones debió animar a la compañía, que el jueves día 22 volvió a dar otra función en la plaza de toros, en esta ocasión a beneficio del joven Eduardo Díaz. Además del beneficiado actuaron las señoritas amazonas, la familia Colmar y la familia Mariani. El espectáculo ese día acabó con una pantomima. En la función celebrada la tarde del domingo, día 25, se distinguieron la familia Colmar y la familia Mariani. También intervinieron la señorita Julia, el célebre Toni y el director señor Díaz. No cabe la menor duda de que estamos ante una de las mejores compañías en su género. Esto hace que, sin tiempo material para recuperarse, esté en condiciones de organizar otra nueva función el lunes día 26. Los ejercicios realizados por la familia Colmar y los verificados por Enrique Díaz en los caballos fueron los que más agradaron. Entre las circunstancias que hacen que una compañía mantenga durante tanto tiempo el interés del público está la presentación de números o artistas nuevos. Ése es el caso de la función que se celebró el jueves día 29. Hicieron su presentación las señoritas Heredia y otros artistas que la semana anterior llegaron procedentes de Lisboa. Durante el mes de mayo se va a prolongar la presencia de Enrique Díaz y su compañía ecuestre en la ciudad, dando funciones en la plaza de toros. El domingo día 2 se distinguieron, además del propio director, su hermano Eduardo, la familia Mariani y Toni Grice. El burro Rigoleto, dirigido por el popular Toni y la pantomima final fueron los números que más agradaron en la función que la compañía ecuestre del señor Díaz dio en la plaza de toros el domingo día 16. Finalmente, a beneficio de la familia Mariani volvió a celebrarse otra función el jueves día 20. Además de los beneficiados intervino la señorita Heredia en los tres trapecios.

Tras unos años de espera para poder presenciar espectáculos de esta naturaleza, el público de Badajoz tiene nuevamente la oportunidad en los comienzos del verano de 1884. El domingo día 8 de junio tuvo lugar en la plaza de toros la primera función de la compañía ecuestre y acrobática en la que trabajaban los hermanos Lecusson, quienes realizaron los ejercicios ecuestres, las bolas terrestres y el tándem. También actuaron los clowns Emili, Rotomagó, Bumbor y Garrocha. Una semana después, el domingo día 15 , nueva función de la compañía dirigida por míster Lecouson. Ofrecieron 
en esta oportunidad los trabajos de los caballos en libertad, presentados por miss Elena, viuda del artista Brun; La fille de fer, por mademoiselle Eugenia Lecouson; saltos mortales a caballo por míster Antoine; la course a grande carrera, por mademoiselle Matilde; el tándem por madame Eugenia y «Bebe caballo excéntrico", presentado por el clown míster Bumbor. También actuaron los clowns míster Esmil y Benavides, artistas brasileños.

Conviene destacar un hecho importante. Los espectáculos comienzan a internacionalizarse; cada vez son más numerosos los participantes con nacionalidad distinta a la española. Esta circunstancia da prestigio a las compañías que consiguen reunir en su nómina a miembros de otros países. Pero en este caso también podemos utilizar el dicho de que no son todos los que están. Es decir, muchos artistas nacionales recurren a un nombre artístico extranjero para despertar de esa manera la admiración e interés del público. Como venimos observando, los apelativos en inglés y francés son frecuentes, sobre todo en esta última compañía.

Resaltemos ahora la función dada el domingo día 22 de febrero de 1885 en la plaza de toros. En ella los sargentos del Regimiento de Caballería exhibieron su proyectado Carrousel para recabar fondos que se dediquen a reparar las desgracias causadas por los terremotos. Es la primera muestra de aficionados locales, aunque profesionales en otra disciplina como es la militar, que, conocedores del poder de convocatoria de este tipo de espectáculo, no duda en aportar su granito de arena por una causa digna de elogio y que, sin duda, obtuvo la respuesta deseada. En este sentido hay que indicar que la asistencia del público siempre fue numerosa, ya se tratara de funciones teatrales, conciertos u otro tipo de espectáculo, máxime si eran benéficas y/o protagonizadas por aficionados.

Pero volvamos a quien con el paso de los años se convirtió en el artista más popular de la ciudad, al menos el que más veces incluyó Badajoz en los recorridos artísticos de su Compañía Ecuestre, Enrique Díaz. En el mes de mayo de 1886, concretamente el domingo día 9, dio la primera función de esta nueva serie también en la plaza de toros. En esta ocasión la novedad está en la que presentación de cuatro Toros amaestrados. Actuaron Aniceta Díaz, los artistas Teresas, el clown Sciler y el joven Eduardo Díaz. Días después ofrecería otra función en la que volvieron a presentarse ante el público Aniceta Díaz, los artistas Teresas, el joven Eduardo Díaz y el propio director, que repitió el número de los Toros amaestrados. La despedida se verificó el miércoles día 12. Actuaron Aniceta Díaz y los artistas Teresas, el joven Eduardo Díaz, el clown Sciler y el director, señor Díaz. También intervino la señorita Amorós que realizó ejercicios de gimnasia. Asimismo volvieron a mostrarse los cuatro Toros amaestrados. 


\section{b) Espectáculos de ilusionismo}

Si el teatro es ilusión por cuanto sirve para mostrar la realidad, nuestra propia realidad, pero interpretada por otros o el mundo de la imaginación, de los sueños, de los imposibles, de episodios y escenas, de lo deseado y no conseguido, algunos espectáculos parateatrales, como los que incluimos en este apartado de ilusionismo han conseguido despertar siempre el interés del público, precisamente por lo inexplicable de sus números y la habilidad demostrada por quienes los protagonizan. A lo largo de estos años que estamos rescatando de la historia de nuestra ciudad también tuvieron hueco en el panorama festivo y contribuyeron al goce y disfrute de nuestros paisanos los espectáculos de ilusión, de magia, de lo «inexplicable» a primera vista.

Como ya comentamos en el apartado anterior, aunque en este grupo se acentúe de manera más considerable, no hemos podido documentar, como hubiéramos querido, el contenido concreto de cada uno de los números presentados. Por ello, debemos dar rienda suelta a nuestra imaginación para hacernos una idea de en qué consistían. El primer registro encontrado lo documentamos en marzo de 1865. La noche del sábado día 18 dio Mr. Velle su tercera función de Espectros vivientes, en la que se presentaron las célebres artistas señoritas Clouss. Estos espectáculos que ya no exigen un lugar amplio y espacioso para su realización, se concentrarán en el teatro. De ahí que para nosotros representen el genuino parateatro: es espectáculo y fiesta, como el teatro, y, además, se ubica en el mismo edificio. No es, pues, de extrañar que para la gente siguiera siendo teatro.

De algo similar debió tratar el espectáculo titulado Sombras impalpables que cerró el concierto celebrado en el teatro del Campo de San Juan, el miércoles día 23 de enero de 1867, por los artistas italianos Maggioco, Tassara y Nicora. Ahora asistimos a un tipo de espectáculo más individual, donde no se movilizan tantos artistas como ocurría en los reseñados en el apartado anterior. Otro tipo de espectáculo que se exhibe a la consideración del público, coincidiendo con la presencia en nuestra ciudad de estos músicos italianos, es el ofrecido a la conclusión de los conciertos celebrados los días 19 y 20 por el Sr. Walter y denominado Cuadros disolventes, muchos de ellos de gran efecto, repetidos el miércoles día 23, tras un nuevo concierto a cargo de los artistas italianos Maggioco, Tassara y Nicora. Los cuadros disolventes entusiasmaron a generaciones de espectadores. Algunos autores han destacado su relación muy estrecha con el teatro, ya que contribuían a reforzar el ilusionismo teatral y el escenario como cuadro y como caja de sorpresas. También Badajoz contó con ellos

Llegamos así al mes de septiembre. Las noches de los días 13 y 15 tuvieron lugar en el teatro del Campo de San Juan sendas funciones de Prestidigi- 
tación a cargo de Mademoiselle Benita Anguinent, quien repitió nuevamente el miércoles 18 y el viernes día 20 . Ofreció suertes difíciles y variadas y «probó cuán partido sabe sacar de sus palabras», según comenta el anónimo cronista, destacando una de las claves que caracteriza al auténtico artista en estas lides: la capacidad de seducir con las palabras y mantener atónitos a los espectadores.

En julio de 1869, en las funciones efectuadas los días 6 y 15 fueron exhibidos al público una nueva colección de Cuadros disolventes, que han aumentado desde la última vez (lo que nos da entender el progreso que este arte había experimentado). En la función del jueves día 15, llamaron la atención los que «enseñan ciertas capillas levantadas para conmemorar la pasión de Jesús, y uno de un célebre pintor italiano»; y las Sombras impalpables. Así, en la misma función del domingo día 18, como fin de fiesta, se repitió este «juguete fantástico».

Muchos de estos espectáculos servían para rellenar los intermedios de las representaciones escénicas que tenían lugar en el teatro e incluso para rematar las funciones, dejando al público con un gran sabor de boca. Eso ocurrió el jueves día 15 de julio, también de 1869, cuando la función celebrada en el teatro del Campo de San Juan se cerró con las Sombras impalpables, que distrajo a la concurrencia.

Este verano de 1869 fue bastante pródigo en acontecimientos parateatrales. A los anteriores hay que añadir los celebrados en el mes de agosto. En la noche del domingo día 1 tuvo lugar en el teatro del Campo de San Juan el espectáculo de recreos de prestidigitación, escamoteo y destreza a cargo de la célebre profesora Elisa Herrero Limiñana, a cuyo término fueron exhibidos unos preciosos cuadros disolventes, que destacaron tanto por la variedad como por sus excelentes condiciones artísticas. Elisa Herrero de Limiñana volvió a dar una función de prestidigitación en el teatro del Campo de San Juan, el domingo día 8, despidiéndose así de nuestra ciudad.

A medida que avanza el siglo el arte de la prestidigitación aumenta en practicantes y en seguidores. Hoy sabemos que es un número que no puede faltar en el repertorio de un mago que se precie de ello, ni de un circo que diga contar con las mejores figuras y los mejores espectáculos. En el devenir del siglo XIX cada vez son más numerosas estas muestras de prestidigitación y más variados los artistas que las presentan. En 1871, el sábado día 18 de noviembre actuó en el teatro del Campo de San Juan el prestidigitador Sr. Nicolay. Lástima que con el aumento en cantidad y calidad que venimos comentando no fuera acompañado de un mayor lujo de detalles por parte de quienes se dedicaban a escribir la crónica de los espectáculos en los periódicos locales. Pero, en fin, será algo que también mejorará con los años. 
Una muestra de este progreso en la descripción de los espectáculos la tenemos dos años después cuando se presenta en nuestra ciudad el señor Fonseca. Para el viernes día 28 de marzo se anunció la función que en el teatro del Campo de S. Juan celebraría este reputado prestidigitador. Se nos dice que el programa de la función constaba de dos partes con el siguiente desarrollo: en la primera parte: sinfonía, un escamoteo agradable, las cartas magnéticas, desaparición de una copa con vino, una sorpresa, el cigarro mágico y las flores misteriosas. En la segunda parte: el huevo chim chim, varias suertes de naipes, el arroz y la naranja, un capricho, las minas del Perú, aparición de 5.530 banderas de todas las naciones, dando fin con el pabellón de Portugal e Italia. No podemos negar, a la vista de este completísimo programa, que el espectáculo de prestidigitación había alcanzado una madurez suficiente como para sostener por sí solo todo un espectáculo, con bastantes garantías de convocar el público necesario que lo hiciera rentable.

Ya mencionamos anteriormente cómo las primeras noticias que tenemos de este espectáculo en Badajoz nos llegan por la participación de Mademoiselle Benita Anguinet, en septiembre de 1867. Sin duda este personaje va a tener para los pacenses la misma popularidad, traducida en concurrencia a las funciones, que la obtenida por Enrique Díaz en las manifestaciones ecuestres. Siete años más tarde, en 1874, más concretamente en junio, inicia esta artista una serie de actuaciones que la van a mantener en nuestra ciudad durante todo el mes, completando diez funciones, lo nunca visto hasta entonces. La noche del lunes día 1 se celebró la primera función dada en el teatro del Campo de San Juan. Se comenta que la artista destacó por la dificultad de las suertes incluidas en el programa, así como por la maestría y limpieza con que fueron realizadas. El jueves 4 y el domingo 7 se celebraron dos nuevas funciones que resultaron entretenidas y variadas, como las celebradas el jueves día 11, el domingo día 14, el viernes día 19 (el beneficio de Mlle. Benita Anguinet) y el domingo día 21, anunciada como la última que celebraría.

Las funciones de beneficio de los artistas era una práctica muy frecuente en todo en mundo escénico y artístico. Las Compañías teatrales, de comedia, zarzuela u ópera, anunciaban así sus últimas funciones, antes de despedirse del público. Solían organizarse dos o tres funciones a beneficio de determinados artistas, generalmente la primera actriz, el primer actor y el director. Con ello se daba a entender que los beneficios económicos obtenidos esa noche los destinaba la empresa a mejorar el bolsillo de estos artistas. El público, que lo sabía, solía acudir en mayor número a estas funciones, siempre que la temporada teatral hubiera sido de su agrado. Estas funciones de beneficio eran también el pretexto que las personas de posición de la localidad utilizaban para mostrar su «adinerada» situación social: hacían regalos a los beneficiados de lo más variopinto que podamos imaginar: carteras, bille- 
teras, pulseras, objetos de tocador, estuches para escritorio, cubiertos, alfileres de corbata, álbumes para retratos, sombrillas, servilleteros y flores, muchas flores, en forma de ramos o coronas, acompañadas de sueltas de palomas y algunos versos. También contribuían al beneficio de los artistas otras personas, renunciando a parte de sus ganancias, como los propietarios del teatro entre otros.

Esta práctica de las funciones de beneficio se trasladó del teatro al resto de espectáculos; por eso no causa sorpresa saber que Mlle. Benita Anguinet, al anunciar su despedida, organizara una función de beneficio. A pesar de ello, esta célebre prestidigitadora no se va de Badajoz. El domingo día 28 verificó una nueva función en el teatro del Campo de San Juan. El espectáculo estuvo dividido en cuatro partes: en dos realizó suertes muy variadas, en la tercera rifó varios objetos y la cuarta se completó con los Cuadros disolventes de $\mathrm{Mr}$. Mordan. Esta cuarta parte nos interesa por un doble motivo. En primer lugar, justifica de alguna manera la permanencia de la artista en la ciudad (algo nuevo debía incorporar a sus espectáculos); en segundo lugar, representa las primeras muestras de asociacionismo entre los artistas, lo que con el paso del tiempo vendrá a significar el circo. De nuevo, el lunes día 29 se celebró una función de Mlle. Benita Anguinet en el teatro del Campo de San Juan en la que rifó diferentes objetos y llegamos así al 5 de julio, domingo, en que se anuncia la última actuación. Volvió a ejecutar suertes distintas, se mostraron los Cuadros disolventes de Mr. Mordan y se efectuó una nueva rifa.

El viernes día 29 de junio de 1877 dio una función en el teatro del Campo de San Juan el joven prestidigitador italiano Serafín Módena, discípulo de Mr. Hermann. Este célebre prestidigitador fue objeto de innumerables parodias por parte de Arderius, creador del Teatro de los Bufos de Madrid. Y es que el circo contribuyó a crear un concepto más elástico del teatro y está aún por determinar cómo influyeron por ejemplo los clowns en los actores cómicos y hasta qué punto se inspiraban unos en otros.

Hay que destacar cómo este arte de prestidigitación es casi terreno controlado por los artistas extranjeros, quienes sin duda han disfrutado de una mayor tradición, que después ha repercutido en su formación, en comparación con los españoles. No olvidemos que las artes escénicas, y con ellas las parateatrales, se mueven al ritmo que marcan corrientes foráneas. Sólo a partir del último cuarto de siglo empezará a vislumbrarse un estilo propio en obras, autores y artistas.

Mientras estos artistas nacionales aparecen, siguen desfilando por nuestra ciudad artistas extranjeros. Éste es el caso del prestidigitador señor Frizzo, quien organizó dos funciones en el teatro del Campo de San Juan: una el domingo día 25 de mayo de 1879 y otra el jueves día 29 . Si esto ocurre en 
mayo, un mes después nos visita el prestidigitador míster Velle. El domingo día 29 de junio míster Velle realizó en el teatro del Campo de San Juan muchas suertes entre el mismo público, que pudo observar hasta los más leves movimientos del artista (con lo que ello supone de perfección y destreza para no ser descubierto). En esta función actuaron Los Niños Florentinos en la parte dedicada al baile. Las funciones continuaron unos cuantos días más. El martes día 1 de julio, también en el teatro del Campo de San Juan, madame Velle ejecutó la novedad del día: el «arca» de Noé. En el espacio de minuto y medio, esa señora, que estaba metida en un saco atada por la boca, salió de éste y entró en un arca cerrada con llaves, cubierta por una lona, atada con dos cuerdas, cuyas puntas habían sido lacradas, sin romper dichas cuerdas. El domingo día 6 míster Velle preparó una nueva función, esta vez en la plaza de toros, animado por el calor veraniego, lo que animaría seguramente al público. Bailaron los niños florentinos y se repitió el número del arca.

Llegamos así al año 1880. El domingo día 3 de octubre dio una función, en el teatro del Campo de San Juan, míster A.E. Neubours de Berlín, realizando distintas suertes de prestidigitación, repitiéndolas el jueves día 7.

Varios años hace ya que no viene a visitarnos Mme. Benita Anguinet. Siete años después de la última vez que actuó en Badajoz, vuelve a lucir su arte. La noche del domingo día 5 de junio de 1881 en el teatro del Campo de San Juan celebra la primera función de prestidigitación. Hasta el jueves día 16, en que se anunció una nueva función, había dado otras dos.

El señor Fonseca es otro artista que vuelve mucho tiempo después. Había actuado en nuestra ciudad en 1873. Ahora, nueve años después, anuncia nuevas funciones. El sábado día 23 de diciembre dio una función en el teatro del Campo de San Juan, realizando varios ejercicios de escamoteo. El día de Nochebuena el prestidigitador portugués señor Fonseca que, por lo esmerado de su estilo se comentaba que cualquiera diría discípulo de míster Sagastini, volvió a actuar en el teatro del Campo de San Juan.

Hasta ahora hemos situado todos los espectáculos de prestidigitación en el teatro, salvo el organizado por míster Velle en la plaza de toros. Pero llega el turno de los locales de aficionados. Como nos dice Díez Borque ${ }^{9}$ :

Las actividades teatrales y parateatrales, en fin, llegaban también a las entidades culturales y a las propias casas donde se formaban grupos de aficionados para poner en escena las obras de mayor éxito del momento y obras clásicas. Es un capítulo más de la intrahistoria teatral del pasado siglo que está por escribir.

9 Ibídem, pp. 750-751. 
La abundancia de sociedades dramáticas y lírico-dramáticas fue enorme aun sin considerar otras instituciones en las que se hacía teatro. Las funciones se llevaban a cabo en la propia casa o palacio y otras veces se alquilaba un teatro de segundo orden. Las motivaciones de los aficionados fueron muy dispares: desde quienes pretendían regenerar el teatro español, a quienes lo hacían como pasatiempo o a beneficio de los pobres y damnificados por alguna catástrofe. En los años finales de siglo, los grupos obreros comenzaron a fomentar el cultivo del teatro como forma de concienciación social, creando su propio repertorio.

En este sentido se anunció en mayo de 1883, sin especificar fecha, la actuación en el Casino y en el Liceo de Artesanos del prestidigitador Cagliosto Och Nabart. Brevemente recordaremos lo que se apuntaba de estos dos espacios en otro estudio que hemos publicado ${ }^{10}$. El Casino de Badajoz fue fundado en 1839 con el nombre de Liceo. Estuvo ubicado en distintos locales, el primero y a la postre definitivo estará en la calle Moreno Nieto (hoy del Obispo). En un folleto anónimo de 1892 se describe diciendo que su decorado es de buen gusto, posee buena biblioteca, un magnífico salón billar, sala de tresillo y conversación, un elegante salón de baile, patio y jardín, restaurante, servicio de correo, telegramas diarios, los periódicos más importantes de España y muchos del extranjero. Por su parte, el Liceo de Artesanos fue fundado en 1852 por don Luis Galindo, ocupando el piso principal del número 10, también de la calle Moreno Nieto. El mismo folleto anónimo lo describe como local bastante espacioso con todas las dependencias necesarias para el recreo de sus socios, el cultivo de las artes y el estímulo al trabajo, objetivos con los que nació. Disponía de un bonito salón de baile bastante capaz y adornado con gusto, con su pequeño escenario portátil para las representaciones teatrales.

Pero sigamos con el recorrido cronológico que venimos haciendo en torno a los espectáculos parateatrales de prestidigitación. Si hasta la fecha los artistas actuaban en solitario o, como mucho, haciéndose acompañar de otros artistas que lucían otras habilidades para rellenar así mejor la función de que se tratara, este año 1883 va a traer hasta Badajoz a toda una compañía en el arte del escamoteo. El sábado día 2 de junio se presentó en el teatro del Campo de San Juan la compañía Zanardelli, al frente de la cual figura la prestidigitadora Enma Zanardelli. Junto al doctor May trabajó en los experimentos de adivinación del pensamiento. En la función participó el prestidigitador señor Onrey. Vemos que el espectáculo se enriquece con más artistas. El domingo día 3 se verificó una nueva función de la compañía Zanardelli. Además de repetir los números de la función anterior, esa noche destacaron lo siguientes: Enma creía oler en los pañuelos no perfumados de los señores

10 SuÁrez MuÑoz, Ángel (1997), El teatro en Badajoz: 1860-1886. Cartelera y estudio. Madrid: Támesis, pp. 36-37 (Producto de la tesis de doctorado, dirigida por el profesor José Romera Castillo, en la UNED). 
E.Balza y Merino los efluvios de rosas y violetas, pensados por dichos señores; el señor Ortega imaginó que la sonámbula viese ante ella un charco de sangre y así lo vio Enma. El señor Urbino deseó cambiarse de asiento y así lo verificó; Jiménez, médico de Olivenza, subió al escenario y le preguntó cómo era su apellido y fue contestado satisfactoriamente. Se cambió la hora a un reloj y Enma la adivinó, señalando las dos y cuarenta y cuatro minutos. El señor Claros preguntó cuántas monedas tenía en su mano derecha y salió satisfecho, diciendo que eran dos, una de plata y otra de cobre. Pero la prueba que agradó más fue la propuesta por el señor Castro. Subió al escenario, colocó en contacto con la frente de Enma un papel y le preguntó qué documento era. La sonámbula dijo: «Es un billete de lotería número 4.861», y así era en efecto. El médico señor Oliveres preguntó qué objeto recordaba en aquel momento. La sonámbula respondió: «Un cuadro de pintura y que es muy bueno»; el señor Oliveres efectivamente confirmó que pensaba en el cuadro de Pradilla, La rendición de Granada.

Como podemos comprobar, nunca antes se había hecho una descripción tan minuciosa de una función de magia o prestidigitación, ni tampoco había participado el público tan directamente como en la función de esa noche. El jueves día 7 volvió a dar una función en el teatro del Campo de San Juan la Compañía Zanardelli, destacando algunas suertes, realizadas por el prestidigitador señor Onrey, y los experimentos del doctor May y Enma Zanardelli.

En la función celebrada en el teatro del Campo de San Juan, el miércoles día 13 de enero de 1886, se presentó en Badajoz el prestidigitador italiano signore Roberto Spinetti que ejecutó modernos juegos de nigromancia. Este artista ofreció dos funciones más, en días sucesivos. Es el primero que se atreve a mostrar una habilidad que debió despertar en nuestros paisanos una gran expectación: la adivinación de sucesos futuros o que pasan a distancia por medio de brujería, más asociada popularmente con la magia negra.

De nuevo un escenario de aficionados acoge un espectáculo parateatral. En el Liceo de Artesanos dio dos funciones, en mayo, el joven prestidigitador Manuel Infantes, realizando suertes variadas. El sábado día 12 de junio y el domingo 13 dio funciones en el teatro del Campo de San Juan el prestidigitador señor Vergara, ofreciendo diferentes suertes.

\section{c) Espectáculos gimnásticos o de funambulismo}

Al tratar este tipo de espectáculo hay que comentar que Badajoz contó con su propia compañía o grupo estable, que llegó a establecerse como Academia dedicada a la formación de los jóvenes en esta faceta gimnástica, fundada por 
Luciano Sampérez. Esta agrupación en torno a la gimnasia compitió con las mejores del país, siendo incluso mejor que muchas de las que pasaron por nuestra ciudad a lo largo de estos años. Podemos, incluso, decir que en este Gimnasio de Badajoz está el origen del primer cuerpo de bomberos con que contó la ciudad.

Por eso, los primeros testimonios conservados y referidos al mundo de la gimnasia y las exhibiciones deportivas tienen como protagonista al grupo organizado por Luciano Sampérez. El domingo día 31 de marzo de 1872 se verificó en el teatro del Campo de San Juan una función de gimnasia. La sección dirigida por Luciano Sampérez ejecutó La pirámide humana, y el joven Tomás Sánchez el Trapecio al vuelo. El niño Teodoro Sampérez, de cinco años de edad, admiró al público con sus equilibrios en la cuerda y Brígido Corchero, con admirable desenvoltura, trabajó en la Caña Bambú casi tan bien y con tanta agilidad como lo hizo el joven del circo de Price, que trabajó en este teatro el año pasado. Los ejercicios en el doble trapecio por los niños Narciso Corchero y Germán Alvarado fueron muy aplaudidos. Los jóvenes Aquilino Clamarón, Fuentes, Corchero, Sánchez y el director Sampérez trabajaron en el Torniquete.

El siguiente registro se sitúa en el otoño de 1874. Concretamente, el domingo día 15 de noviembre se celebró una función gimnástica. El joven Aquilino Claramont trabajó en el torniquete; los niños Guillermo, Aniceto y Antonio trabajaron juntos en el trapecio. En el doble trapecio se destacaron Claramont y Cuervo.

Toda la historia de esta compañía o institución que se denominaba Gimnasio de Badajoz la hemos ido recogiendo entre líneas, a medida que rescatábamos cada una de sus actuaciones. Es en esa reseña que hacía el articulistas del periódico donde encontramos datos que amplían nuestro conocimiento y nuestra información sobre ese establecimiento. El siguiente registro se fecha en 1875. El domingo día 6 de junio el Gimnasio, fundado por los señores Sampérez y Crespo, celebró otra función. El joven Aquilino Claramont trabajó en los trapecios y en la arriesgada suerte que en los programas denominaban de «los leones». Tomás Sánchez y Antonio Gómez trabajaron en las anillas y en el torniquete; los niños Antonio y Dionisio Alonso hicieron los equilibrios en el trapecio y en bambú respectivamente. La función se verificó a las 5 de la tarde. El domingo día 13 se ofreció una nueva función de gimnasia en la que se expusieron los mismos ejercicios que la vez anterior.

Hemos ido comprobando cómo según el tipo de espectáculo parateatral de que se trate así será más propicio un escenario u otro. Si para los números ecuestres era más aconsejable la plaza de toros, para los ejercicios de magia o prestidigitación venía mejor un recinto más cerrado e intimista, si se quiere. 
Pues bien, ahora para los ejercicios gimnásticos los escenarios serán alternativos. Lo mismo se prefiere el recinto acotado de un teatro como la expansión que provoca la calle. Por eso no extraña que, dedicada al Ayuntamiento, se celebrara el domingo día 1 de agosto, por la noche, una función de gimnasia en la calle de Chapín. No se especifica si dentro de algún local, porque nos consta que en esta calle existía lo que se conocía como un circo, donde actuarán estos gimnastas más adelante, exactamente el domingo día 19 por la tarde, verificándose una variada función acrobática. Los señores Sampérez y Claramont ejecutaron por primera vez ejercicios en la doble barra. Los juegos icarios, que estaban anunciados, no pudieron ejecutarse por falta de tiempo, pues ya de noche se realizó la suerte conocida con el título de El hombre volador.

La ventaja de esta agrupación, al ser de la localidad, es que cuenta con su propio local. De ahí que en muchas ocasiones celebren sus actuaciones en dicho Gimnasio. De nuevo el jueves día 5 en el local del Gimnasio se dio una función en la que intervinieron el director Sr. Sampérez y los jóvenes Claramont y Gómez. Actuó el clown Sr. Rozner que, habiéndose separado de la Compañía de Ferroni, se brindó a tomar parte en la función.

Pero no todos los espectáculos gimnásticos van a estar monopolizados por la agrupación gimnástica de Luciano Sampérez. En septiembre de ese mismo año 1875 , en concreto la noche del jueves día 16 , se verificó la primera de las funciones que se propuso dar la Compañía de Acróbatas italianos, espectáculo nuevo en Badajoz, resultando muy meritorias las decoraciones. También son foráneos los artistas que se presentan en nuestra ciudad en febrero del año siguiente. En esta ocasión es la plaza de toros la que les acoge. El miércoles día 2 celebraron una función gimnástica los hermanos Crolans, en la que también tomaron parte algunos aficionados del Gimnasio artístico, dirigido por el Sr. Sampérez. Los ejercicios más destacados fueron: los trabajos en la barra fija, en los que tomaron parte los aficionados Claramunt y Cuervo; los ejercicios sobre el trapecio aéreo, por el niño Alonso; los ejercicios en el doble trapecio, en el «puente de la muerte» y los «vuelos aéreos» que ejecutaron los hermanos Crolans, realizando el salto mortal con los ojos vendados y la cabeza metida en un saco. Los hermanos Crolans realizaron una nueva función gimnástica el domingo día 6 también en la plaza de toros. En dicha función participaron los aficionados Claramunt y Cuervo, y el niño Alonso. Un mes después, el domingo día 5 se verificó, igualmente en la plaza de toros, una función de gimnasia en la que tomaron parte los hermanos Crolans y los clowns señores Pichelet. Entre los ejercicios que se ejecutaron destacaron: los anillos aéreos, la barra y el doble trapecio, en los que actuaron los hermanos Crolans. También agradaron El pasatiempo cómico de los hermanos Pichelet y los saltos mortales sobre la Baluda francesa (sic), en los que se distinguió uno de los clowns. 
Este largo párrafo nos permite realizar otro comentario de interés. La afición por lo teatral y lo parateatral, en resumen por el mundo de los espectáculos, es tan grande durante el siglo XIX que la gente no se limita a verlos, sino que gusta practicarlos. Surge el teatro y el espectáculo en general casero, hechos por aficionados que se sirven de locales alquilados para la ocasión. Algo ya habíamos dicho al respecto. Pero ahora nos interesa recalcar otra idea. Jean-François Botrel ${ }^{11}$, otro estudioso del teatro del siglo XIX, ha insistido en el carácter popular que el teatro llegó a tener, convirtiéndose en el medio de comunicación social más extendido. Cita un número muy considerable de teatros o asociaciones de aficionados activas a finales de siglo situados, la mayoría, fuera de las capitales de provincia. Asimismo destaca que compañías profesionales representasen en pueblos e, incluso, que en estos pequeños núcleos de población existiesen grupos de aficionados con la capacidad de ayudar a los profesionales en sus actuaciones. Lo aquí apuntado también puede aplicarse a lo parateatral. Vemos cómo los aficionados del Gimnasio del señor Sampérez colaboran con los profesionales hermanos Crolans en el desarrollo de una función.

Más artistas extranjeros invaden la escena y el mundo del espectáculo de nuestra ciudad al llegar el verano de 1875. En el mes de agosto los árabes beduinos de la tribu de War dieron el domingo día 27 una función en la plaza de toros en la que tomó parte el célebre equilibrista señor Ayala. Actuaron además los artistas Sechi, Bobbi, Giovanni y Rafael, así como otros «notables grupos» de la compañía marroquí.

Tendremos que esperar más de dos años para encontrar la siguiente referencia a espectáculos sobre gimnasia o funambulismo en Badajoz. En diciembre de 1877 la compañía de Gimnasia dirigida por Juan Meni trabajó en la plaza de toros el sábado día 8. En ocasiones los aficionados de la localidad se atrevían sin reparo alguno a «competir» con los profesionales que en esos momentos actuaban en la misma. Además, la función que ahora comentamos nos sirve también para ilustrar cómo llegaron a convivir en armonía teatro y parateatro, cómo cada uno servía, aunque de distinto modo, al otro. El asunto es que el Gimnasio de Sampérez actúa estando en Badajoz la compañía de Men. Así, la tercera parte de la función celebrada el miércoles día 19 en el Conservatorio de la Orquesta Española incluyó la ejecución de ejercicios en el trapecio y la barra a cargo de los discípulos del señor Sampérez. Observamos cómo un espectáculo más próximo al circo sirve de complemento a una función teatral propiamente dicha. Esta combinación debió resultar interesante porque se repetirá el jueves día 4 de abril. El con-

11 BotREl, Jean-François, «El teatro en provincias bajo la Restauración. Un medio popular de comunicación». Bulletin Hispanique LXXIX, 3-4 (1977), pp. 381-393. 
cierto celebrado también en el Conservatorio de la Orquesta Española incluyó en su programa la actuación de los gimnastas que preparaba el señor Sampérez.

La Compañía de Meni va a dar algunas funciones más en Badajoz. En enero de 1878 dio otra función en la plaza de toros, exactamente el domingo día 6, agradando mucho a la concurrencia los ejercicios que hicieron todos los artistas que en ella tomaron parte.

En abril nos encontraremos con una compañía singular que mezcla en sus espectáculos lo ecuestre con lo gimnástico o acrobático, incluso se autodenomina zoológica. El jueves día 11 la compañía que dirigen los señores Edmons, Onra y Mayols celebraron una función en la plaza de toros. Llamaron la atención los ejercicios que míster Onra realizó con los tres trapecios. Hasta aquí, más o menos lo que ya sabemos que hacen otras compañías. Pero el domingo día 14 se anunció otra función de la compañía «ecuestre y zoológica» que tendría lugar en la plaza de toros. En la misma el señor Onra haría el ejercicio de El hombre en el obús y Mme. Mayols repetiría La hija del regimiento (parodia de la zarzuela del mismo título en tres actos escrita por Emilio Álvarez y música de Donizetti); también actuaría el pequeño jockey.

En mayo nos visita la compañía de acróbatas milaneses que anuncian una función para el jueves día 30 en la plaza de toros. El domingo día 2 de junio repiten función. En esta ocasión intervinieron los señores Acosta y Miller. El mismo señor Acosta en la barra, y el niño Miller y el señor Listó en la suerte Los arrojos del despeñadero. Una semana después exhibe nuevos números: el domingo día 9 los señores Acosta y Míler participaron en la suerte de los Vuelos terroríficos. La señorita Fanny actuó en la pantomima. La función concluyó con la lidia de un toro. Ahora entendemos lo de compañía zoológica. Es la primera compañía que se atreve a torear, no siendo profesionales de ello.

Ya comentamos antes que la agrupación local constituida en el Gimnasio propicia que en su seno surja el primer servicio de bomberos conocido en la ciudad. Así lo deducimos cuando sin concretar fecha se nos dan a conocer las dos funciones verificadas en la plaza de toros por la Compañía de Bomberos del municipio dirigida por Luciano Sampérez. Además de los ejercicios de gimnasia, demostraron su pericia en el espectáculo de la casa incendiada. Estamos en los primeros días del recién estrenado año 1881.

De nuevo un lapsus prolongado de tiempo antes de encontrar nuevos artistas. Estas lagunas en el tiempo que caracteriza a los espectáculos parateatrales tienen su explicación. Sólo se prodigan éstos cuando se produce un vacío en cuanto a representaciones escénicas se refiere. Así, hasta abril de 1882 no nos encontramos con la funambulista Mis Zarah, que el sábado día 1 de abril 
dio una en el teatro del Campo de San Juan; función que se repetirá el domingo día 2 en el mismo escenario.

Gran expectación debió levantar en el público de Badajoz la presencia de una compañía gimnástica americana. Bien ha valido esperar tantos años para ello. Corren los primeros fríos días de enero de 1884. El domingo día 20 tiene lugar en la plaza de toros la anunciada función de gimnasia de la Compañía norteamericana. Destacaron míster Ernesto y Duborg en Las anillas volantes; monsieur Fernan en sus arriesgados equilibrios en el alambre; míster Noel y el clown Franqua en el aparato la barra americana; mademoiselle Aleixandrine en sus juegos; miss Perina y míster Fernan en la doble barra aérea, terminando miss Perina con un ejercicio que la coloca a la cabeza de las principales artistas de su género. La función se acabó con una pantomima. Por lo variado del repertorio y la diversa nacionalidad de los intervinientes podemos afirmar que nos encontramos ante un verdadero circo, tal y como lo hemos conocido quienes ahora somos testigos de la historia.

Finalmente, para cerrar este apartado de espectáculos, que hemos reservado a la gimnasia y al funambulismo, comentaremos que, pocos días después de inaugurado el teatro López de Ayala, visita Badajoz la Compañía excéntrica, musical, acróbata, pantomímica del Circo Price Hipódromo de Madrid, compuesta por 10 artistas, dirigidos por el señor Crolans. Para el sábado día 25 de diciembre, día de Navidad, se anunció una función, sin determinar el lugar. Actuaría también la troupe Balaguets (sic), compuesta por 6 personas, que realizarían los números denominados pop puvú (sic) y juegos orientales. Esta función se repetiría al día siguiente. Los hermanos Crolans ya habían visitado anteriormente nuestra ciudad. En esta ocasión se presentan con una compañía integrada en el Circo Price de Madrid, que junto al de Paul fueron los principales impulsores de estos espectáculos.

\section{d) Espectáculos con fieras y animales domesticados}

Otro tipo de espectáculo, que solía ofrecerse inicialmente separado de un contexto más amplio como en el que hoy englobamos al circo, era el de las galerías de animales domesticados.

La primera manifestación del mismo en nuestra ciudad se ofrece en 1879 en una casa particular y sin que sepamos bien quién la presenta. Así en $L a$ Crónica del día 13 de enero se dio a conocer que ese mismo día se abría al público una exposición de fieras en una casa de la calle de la Sal. 
No debió ser, sin embargo, un espectáculo lucrativo y rentable porque se prodiga poco. Baste decir que el siguiente testimonio documental sobre un espectáculo similar lo registramos, nada más y nada menos que en 1885. El martes día 15 de septiembre se celebró en la plaza de toros la riña anunciada entre el perro invencible y una pantera de la colección zoológica del señor Cavanna y compañía, de la que resultó tener que variar de nombre el perro, pues fue vencido y muy maltratado. Estas peleas a la vista del público no solían ser frecuentes. Lo más habitual era la exhibición de los animales en sus jaulas o ejercicios amaestrados con ellos. Así, este mismo artista anunció para el martes día 20 de octubre la apertura al público de un pabellón zoológico establecido en el paseo de San Francisco. El «numerito» entonces consistía en observar cómo el domador daba diariamente de comer a las fieras a las 8 de la noche. Unos días después se ofrece una variación. Para el sábado día 31 se anunciaron por primera vez los ejercicios con monos, perros y cabras amaestradas en el pabellón del señor Cavanna y compañía. Este espectáculo sí debió contar con el beneplácito del público, porque el jueves día 5 de noviembre volvió a anunciarse la exposición zoológica. Se señala la hora, de tres a seis de la tarde, habiendo diariamente una función de ocho a diez de la noche con los perros, monos sabios y cabras amaestradas. Para el domingo día 8 se anunciaron dos funciones en el Pabellón de la exposición zoológica: una, a las tres de la tarde y otra, a las ocho de la noche, trabajando en ambas los perros, monos sabios y cabras amaestradas. Con las funciones que celebre los días 6 y 7 de diciembre, dos cada día a la misma hora que las mencionadas anteriormente, se despidió este artista que ha estado en la ciudad tres meses.

\section{e) Otros espectáculos}

Agrupamos en este último apartado aquellos otros espectáculos que se ofrecen al público de nuestra ciudad de manera excepcional. Vamos a incluir exhibiciones de figuras y ventriloquía.

El primer espectáculo de este grupo tiene lugar el lunes día 4 de noviembre de 1867, por la noche, en el teatro del Campo de San Juan. Se verifica ese día la primera función anunciada por la Compañía americano-española de «cuadros mímico-plásticos históricos, aéreos, mitológicos y fantásticos» (sic), que dirige el señor Farriol. Vale la pena reproducir literalmente la opinión que lo visto despertó en quien hizo la crónica: Destacó «la prodigiosa exactitud en la esposición (sic) de las escenas mitológicas, de esas escenas que pueden considerarse hijas de la 
ignorancia y debilidad del género humano en tiempos remotos y del desvarío de imaginaciones exaltadas en época no tan lejana. A siete ascendió el número de estos [cuadros]; y debemos, no obstante, hacer especial mención del que representó la batalla que las Amazonas comandadas por su reina Pantasalén ganaron en el sitio de Troya»12. Este espectáculo debió ser muy parecido a los cuadros disolventes que hemos comentado en otro punto de este artículo.

Otro espectáculo fue la ventriloquía, rara habilidad por entonces. En 1869, el martes día 6 de julio, en la misma función en la que actuaron los artistas italianos Maggioco, Tassara y Nicora, actuó el ventrílocuo señor Verned que volvió a lucir sus ejercicios de ventriloquia en las funciones celebradas en el Teatro del Campo de San Juan el jueves día 15 y el domingo día 18.

Siguiendo el correr cronológico de los años, tenemos en 1878 que el señor Eduardo Globe, dueño de una gran galería de figuras eléctricas, abrió la misma en el teatro del Campo de San Juan, el sábado día 13 de julio. Según el prospecto repartido, el señor Globe había sido premiado en las exposiciones de Londres, París, Viena y Filadelfia por sus notables objetos de cristal fabricados en presencia de los espectadores. Entre los cuadros de que consta la galería figura el de Comuneros de Castilla, el de la muerte del general Concha (sic) en la acción de Montemuro en el que se ven los heridos, los señores de la Cruz Roja curando a éstos, etc.; y el asalto de la Seo de Urgell. El señor Globe da también lecciones de su arte y fabrica pájaros y perros de cristal en presencia de los visitantes.

En 1879 los días 10 y 11 de diciembre actuó en el teatro del Campo de San Juan Míster Biberons (sic), quien, además de dar a conocer el fonógrafo, hizo algunas suertes de prestidigitación.

Para concluir este recorrido que hemos venido haciendo por las manifestaciones festivas, emparentadas con el teatro, de las que se tiene constancia, celebradas en Badajoz antes de la inauguración del teatro López de Ayala, que como hemos dicho, marca un antes y un después, debemos citar que para el lunes día 18 de agosto de 1884 se anunció la apertura en el paseo de $\mathrm{S}$. Francisco de un gabinete con figuras de cera y, casi dos años después, el día 19 de julio de 1886, la celebración de un nuevo espectáculo consistente en la elevación de fantoches, mostrándose cómo se elevan a una altura considerable hasta que se pierden en el espacio figuras de tamaño natural, representando titiriteros, soldados, bailarinas, gendarmes, pescados o animales de diversas clases hasta un número de 12 .

12 Crónica de Badajoz, número 274 (sic), de 8-XI-1867, p. [3]. 


\section{LOS ESPECTÁCULOS PARATEATRALES SEGÚN LA CRÍTICA}

Ya hemos comentado antes que nos resulta prácticamente imposible concretar los pormenores de los espectáculos referidos porque no se dan detalles de ellos. A pesar del carácter popular de estas manifestaciones festivas y escénicas que llenan el siglo XIX, sobre todo en su segunda mitad, y de que han llegado hasta nosotros, gracias al importante papel que empieza a jugar la prensa escrita, existe aún una serie de condicionantes, representados principalmente por la censura, que limitan las crónicas y referencias que se hacen de estos espectáculos en los medios de comunicación social de entonces.

Esa censura no sólo obliga al crítico a esconderse detrás de seudónimos más o menos llamativos y originales, sino que reprime gran parte de la capacidad expresiva, reducida en muchos casos a dar a conocer el espectáculo celebrado sin más. Afortunadamente, con el paso de los años, iniciándose el cambio de orientación desde 1868 , el crítico irá desvelando su identidad, no tendrá reparos a la hora de firmar sus juicios y valoraciones, lo que también influirá en un mayor margen de maniobras y libertad expresiva, que redundará en mayor lujo de detalles a la hora de describir y analizar el acto público presenciado o celebrado.

La censura fue especialmente dura con el teatro y las manifestaciones parateatrales debido a su mayor proyección pública. En el periodo comprendido entre 1823 y 1833 , existió una doble censura, la eclesiástica y la política. Tras la supresión de esta última, según la ley de prensa de 1834, se acordó que fuese censor de los teatros uno de los de prensa, velando porque el desarrollo de los espectáculos fuera apropiado.

Como esta doble misión del censor suponía en la práctica mucho trabajo en 1836 se volvió a restablecer la figura del censor de teatros, mantenida hasta 1840 en que se creó la Junta de Censura, compuesta por tres miembros, en vigor hasta los últimos años de la década de los cincuenta. A comienzos de 1857 se suprimió dicha Junta, desempeñando entonces sus funciones un censor especial. Así hasta 1868, año en el que, con el triunfo de la revolución, fue decretada la libertad absoluta.

Durante la Restauración se volvió a legislar sobre el asunto y, aunque no existe la censura previa, sí proliferan las recomendaciones a los Gobernadores provinciales para que extremen su celo, a fin de evitar abusos en las representaciones y faltas a la moral y buenas costumbres.

Aun con censura, se establecieron algunas medidas para garantizar los derechos de autores y cómicos. Quedaba, en cambio, a criterio de la autori- 
dad municipal valorar si las circunstancias aconsejaban autorizar o impedir una representación o un espectáculo, así como vigilar que los actores y protagonistas evitaran las palabras y ademanes que pudieran ofender al público.

Aparte de la censura teatral, ejercida por el Estado, se dio una censura arbitraria, ejercida por grupos de presión, como la Iglesia y el Ejército. Destaquemos, por curiosa, la publicación citada por Cotarelo y Mori ${ }^{13}$ sobre el Sentido Moral del Teatro, del marqués de Valmar, impreso en 1868:

Hoy importa a la dignidad de las letras y al decoro mismo de la civilización, señalar el deplorable estado a que ha venido a parar el teatro de nuestros días. Como agente de relajación de ideas y sentimientos, el teatro puede ser en extremo activo y poderoso, si la sensatez y el buen gusto de los autores, a par que la vigilancia de los gobiernos no ponen estorbo a su depravación moral. Y como estos frenos son a veces laxos o imaginarios y una gran parte de la sociedad, osada. indiferente o pervertida, alienta con su tolerancia o con su aplauso, las censurables audacias de la escena, el mal prepondera sobre el bien en el teatro, y dan aparente motivo a austeros moralistas para abogar por la supresión de tan sabroso esparcimiento.

No obstante, preferimos el comentario de Larra, citado por José Luis Aranguren ${ }^{14}$ :

... el teatro tiene poquísima influencia en la moral pública; no sólo por la forma, sino que sigue él, paso a paso, su impulso. Lo que llaman moral pública tiene más hondas causas: decir que el teatro forma la moral pública, y no ésta al teatro, es invertir las cosas, es entenderlas al revés...

En el periodo que nosotros hemos elegido para describir los espectáculos festivos y parateatrales desarrollados en la ciudad de Badajoz, aún es evidente y ejerce su efecto nocivo sobre la extensión y calidad de la crónica periodística la censura.

Un rápido recorrido por las fuentes documentales que nos suministran los datos apuntados, nos muestra un panorama descorazonador. Todas las noticias referidas al teatro del Campo de San Juan y sus funciones, así como sobre los demás espectáculos, aparecidas en La Crónica de Badajoz (a partir del número 464 de 23 de Junio de 1870, La Crónica) desde el comienzo de

13 COTARElo y MORI, Emilio (1904), Bibliografía de las controversias sobre la licitud del teatro en España. Madrid: Est. Tip. de la Rev. de Archivos, Biblotec. y Museos, p. 582.

14 ARANGUREN, José Luis (1970), «Moral y sociedad. La moral social española en el siglo XIX». Madrid: Edicusa, p. 123. 
nuestro estudio, así como las aparecidas en el Boletín Oficial de la Provincia o en el Avisador de Badajoz, no registran firmas. En el caso de La Crónica de Badajoz, al final del periódico, en la última página, se leía: «Por todo lo no firmado, el editor responsable. Antonio Márquez Prado».

Tras la revolución del 68, en el número correspondiente al día 3 de octubre, además de verse en la cabecera el añadido de «Periódico Liberal», deja de aparecer la referencia citada en el párrafo anterior, que se mantendrá hasta 28 de diciembre de 1875. Aunque La Crónica es el periódico que aporta la gran mayoría de datos para conocer los pormenores del teatro y parateatro en Badajoz, hemos obtenido información en otras fuentes.

Por lo que respecta a El Avisador de Badajoz hay que decir que las críticas teatrales tampoco van firmadas y, como en La Crónica, se hace responsable el editor Gerónimo Orduña. Finalmente, las críticas recogidas de El Eco de Extremadura van sin firmar y sin remitir a editor que se responsabilice de lo no firmado.

En el número 863, del 8 de Enero de 1876, de La Crónica aparecen unos comentarios sobre espectáculos firmados con las iniciales de $E l S$. de C. En el número siguiente del mismo periódico, se incluye la crónica de un concierto celebrado en el Liceo Casino, firmando como El solitario de Caya, que parece ser la correspondencia exacta de las iniciales anteriores. Los números 1028, 1029 y 1030 de La Crónica, correspondientes a los días 23 y 28 de abril y 3 de mayo, respectivamente aparecen con una sección de Variedades en la que se da cuenta de las funciones dramáticas celebradas en la ciudad. Esta sección va firmada por un tal Horse Whip.

En el Diario de Badajoz del 18 de julio de 1883, número 250, aparece la crónica de sociedad del concierto celebrado en el teatro para intentar cambiar la situación del hijo de un artista destinado a Cuba. El artículo aparece firmado por Zoilón de Carrión. El número 345 también del Diario de Badajoz ve personalizada la crónica teatral con la firma de Maneli. En la del día 14 de noviembre, número 350, aparecen las iniciales S.M. En el número 397, de 11 de enero de 1884, firma P.P. En este diario, como podemos comprobar, las firmas de los comentarios teatrales son de lo más diverso. El correspondiente al número 452 del 15 de marzo lo firma un aficionado. El comentario a la reunión celebrada por el Casino el domingo día 13 de abril está firmado por $C$. Nueva, aparecido en el número 476 correspondiente al 15 de abril de 1884 .

En el número 1.716 de La Crónica se da cuenta, entre otras cosas, de la función celebrada en el Conservatorio de la Orquesta por los aficionados, firmando Aljamiabt. El Diario de Badajoz, en su número 1.259 del 2 de noviembre, incluye la crónica de la inauguración del teatro López de Ayala, 
firmada por Sesenta céntimos. Los números correspondientes a los días 4, 5, $9,17,18,19,20,21,23,25,26,27$ y 30 de noviembre, así como los de los días $2,23,28,29$ de diciembre, incluirán crónicas teatrales firmadas con el seudónimo de Cualquiera. Nadie firmará las referencias al espectáculo teatral en los números correspondientes a los días $6,12,13,28$ de noviembre y 1 de diciembre.

Las de los días 11 y 16 de noviembre irán firmadas por Otro Cualquiera (por indisposición de Cualquiera, al menos así se indica). Finalmente la del día 14 de noviembre llevará la rúbrica de $A$. Shesse. Las crónicas de $E l$ Avisador de Badajoz de los días 11, 18 y 25 de noviembre y 9,16 y 23 de diciembre, irán firmadas por Melodías.

Todos estos datos vienen a confirmarnos el crecimiento tan importante que, a partir de 1876, adquieren los críticos teatrales que parecen no sentir reparos a la hora de firmar lo que escriben en los periódicos. No obstante, siguen amparados en el anonimato que, sin duda, les haría sentirse más seguros y a recaudo de sus detractores.

A pesar de que la parquedad de palabras y argumentos es la tónica dominante en las crónicas teatrales y de espectáculos en general, de vez en cuando encontramos las famosas excepciones que «confirman la regla». En esas ocasiones en las que el crítico, escudado en su anonimato o escondido en su seudónimo, se explaya en sus juicios y valoraciones, encontramos un elemento que a nosotros nos interesa especialmente: conocer aspectos que enriquecen nuestra información acerca del espectáculo aludido.

Por eso, toda la cronología que hemos dado a conocer en el apartado anterior de este artículo se completa cuando tenemos en consideración los puntos de vista de los críticos que prestaban su servicio en los periódicos de la época. De ahí que también conozcamos datos y pormenores de los que hemos denominado «parateatro y otros espectáculos» a través de estas apariciones, todavía escasas, de los que ejercieron, nunca mejor dicho, de notarios de una realidad social y cultural en una ciudad como Badajoz y en un periodo, tan intenso como poco estudiado todavía, como fue el siglo XIX.

En general, de los espectáculos parateatrales se suele destacar la calidad de los artistas y la perfección alcanzada en sus números, siendo en todos los casos, críticas positivas. Si acaso, el único descontento o «pero» que suelen señalar es el que sea el teatro el escenario de algunos de esos espectáculos, sin duda debido al deseo de dignificar un arte y un espacio.

La primera referencia crítica que encontramos combina dos aspectos: la importancia del espectáculo, que alivia la crítica, y la no conveniencia de ubicarse en los teatros. Así sucede al referirse a los Cuadros mímico-plásti- 
cos del señor Farriol: «Aunque no estamos conformes con que este género de espectáculos se verifique en los teatros por ser muy diferentes al objeto de los mismos a la tendencia que dominó para la creación de aquéllos y la utilidad que indudablemente reporta a la sociedad su conservación, sin embargo, como hayamos admirado en la compañía Farriol una exactitud prodigiosa en la exposición de las escenas mitológicas...; como para dar vida, animación e interés a esas escenas tan ridículas en su esencia sea necesario el auxilio del genio... detenemos nuestro paso para rendirle el homenaje que se merece...» 15 .

De la prestidigitadora Elisa Herrero Limiñana se comenta que: «... es una elegante y graciosa andaluza que entretiene y cautiva con sus chispeantes ocurrencias propias del privilegiado suelo que la vio nacer, y una notable artista que honra cumplidamente la memoria de su esposo y maestro Sr. Limiñana, uno de los más acreditados prestidigitadores que hemos conocido y a quien el arte debe mucho, pues fue el creador de la nueva escuela que hoy siguen todos los que se dedican al difícil arte de la magia blanca. Los diferentes juegos que nos presentó la Sra. Elisa en la noche a que nos referimos, y que forman una pequeña parte de su inagotable repertorio llamaron notablemente la atención del público, que los aplaudió con entusiasmo, tanto por su novedad como por la limpieza y maestría con que fueron ejecutados. Podemos asegurar que la Sra. Elisa nos hizo pasar una noche deliciosa, engañándonos a cada paso con una gracia sin igual. Para conseguirlo tiene en su favor además de su diabólica habilidad, el no flojo privilegio de ser mujer» 16 .

Aunque hemos dejado fuera intencionadamente los espectáculos musicales, baste una muestra para hacernos una idea de qué se solía comentar de estos espectáculos. En relación con el Concierto de Arturo F. Reinhardt en el Casino, celebrado en julio de 1871, se dice: «Imposible es dar a nuestros lectores ni aproximada idea de cómo este profesor arranca de un instrumento dispuesto para producir roncos sonidos, toda la dulzura que tienen las notas de un violín. Estos prodigios sólo se explican cuando el que los admira sabe lo que es un artista: un ser privilegiado y misterioso que tiene más de Dios que los demás seres, y que del caos informe del sentimiento hace surgir el mundo de la belleza... Nosotros le felicitamos por ello de todo corazón y le aplaudimos cariñosamente como si fuese un artista español, que no son extranjeros para nosotros los portugueses» 17.

Respecto a la Función de gimnasia del domingo día 2 de octubre de 1873, celebrada por los aficionados del Gimnasio de Badajoz, como sabemos diri-

15 Crónica de Badajoz,, número 274 (sic), 8-XI-1867, p. [3].

16 Crónica de Badajoz., número 399 (sic), 3-VIII-1869, p. [3].

17 La Crónica, número 540, 13-VII-1871, p. [3]. 
gido por el señor Sampérez, se comenta: «El público aplaudió ruidosamente al niño Teodoro Sampérez, de cinco o seis años de edad que con gran desembarazo ejecutó difíciles equilibrios en la cuerda, así como también demostraron su serenidad los jóvenes Cortés, Alonso y López» 18.

Sobre este tipo de espectáculo hay más comentarios. Ya hemos mencionado que el domingo día 15 de noviembre de 1874 se celebró una función gimnástica en la que intervino el joven Aquilino Claramont. El análisis que se hace de su actuación fue: «El joven Aquilino Claramont, con su ya musculatura atlética, trabajó en el torniquete, como lo han hecho aquí otros gimnastas que se han llevado el dinero; se desprendía de la barra dando el salto mortal y cayendo al suelo con seguridad, tan bien que arrancaba aplausos sin uno darse cuenta que aplaudía. Los tres niños Guillermo, Aniceto y Antonio, que trabajaron juntos en el trapecio, agradaron bastante por la desenvoltura, la gracia y el desenfado con que lo hicieron. El niño Antonio Alonso hizo algunos equilibrios en el trapecio, con más arrojo, más serenidad y más limpieza que los que han hecho aquí gente de oficio. De rodillas sobre el trapecio, se levantaba, poniendo los dos pies a un mismo tiempo sobre la barra, y se sentó en la silla sobre los dos palos de atrás con gran serenidad. En el doble trapecio se distinguieron bastante Claramont y Cuervo, revelando sobre todo el primero una fuerza muscular envidiable» 19 .

En ocasiones, más que los espectáculos en sí, se valora la iniciativa de sus promotores. Así en la Función inaugural del Gimnasio, celebrada el día 6 de junio de 1875 se comenta: « ... hoy aplaudimos también desde las columnas de nuestro periódico, primero al Sr. Sampérez, director del gimnasio, que con su perseverancia, digna de elogio, ha conseguido, al fin, en medio de la indiferencia y del egoísmo que aquí predominan, hacer algo útil para los demás; al Sr. Crespo, después que siendo un pobre aldeano, ha invertido parte de sus ahorros en la realización del pensamiento del Sr. Sampérez; y, por último, a los jóvenes que contribuyeron con su aplicación al prestigio de su director, poniendo a la vez delante de los ojos de todos, la utilidad del gimnasio y proporcionando a la capital un espectáculo entretenido y poco costoso... no podemos menos que mencionar al joven Aquilino Claramont que trabajó con mucha limpieza y arrojo en los trapecios y sobre todo en la arriesgada suerte que los programas denominaban "de los leones". También merecieron justos aplausos del público en los ejercicios de las anillas y en el torniquete, los jóvenes Tomás Sánchez y Antonio Gómez, que trabajaron sin exagerar, como consumados gimnastas... El niño Antonio Alonso, que hizo los equilibrios en el trapecio, no pudo estar mejor. Contemplabale la concurrencia con

18 La Crónica, número 702, 13-X-1873, p. [3].

19 La Crónica, número 782 (sic), 18-XI-1874, p. [3]. 
asombro, sentarse en la silla y cruzar los brazos con una serenidad y una valentía impropia de sus años. No menos digno de elogio es el niño Dionisio Alonso, que trabajó en el bambú como lo hizo aquí en el teatro Mr. Enrique, de la Compañía de Price ¿Quién duda que merece verse un niño de diez años trabajando lo mismo que un gimnasta que ha llamado la atención en los circos de Madrid?» 20.

De la compañía ecuestre dirigida por Enrique Díaz que el domingo día 17 de febrero de 1878 dio su primera función, como ya comentamos anteriormente, no caben más que elogios: «Toda la compañía es buena; pero cuando aún no trabajasen más que la familia Martini, ella sola conseguiría que el público saliera satisfecho del espectáculo» 21 .

La función dada el jueves día 11 de abril de ese mismo año por la compañía gimnástica y zoológica, dirigida por los señores Edmons, Onra y Mayols ocasionan los elogios del crítico: «Los trabajos que los artistas que la componen hicieron el jueves fueron en verdad notabilísimos y el público no cesó de aplaudir en toda la tarde» 22 .

El prestidigitador Mr. Velle dio una función en la plaza de toros la noche del domingo día 6 de julio de 1879, defraudando las esperanzas del público. Se dice: «La luz hizo el fiasco y como las de las farolas a la veneciana y las demás luces que en la plaza habían eran insuficientes para iluminar el local, éste era demasiado oscuro. No es de extrañar, pues, que la concurrencia se espantara y manifestara ruidosamente su disgusto. Mr. Velle, en una hoja que ha publicado, y que voy a reproducir, consigna que el viento fue la causa principal de que la iluminación no luciera y que algunas personas rompieran, aunque no intencionadamente, cuatro tubos de la comunicación eléctrica. Y, por este motivo, perdió todo su efecto. Añade que el viento rompió también la tela de los cuadros disolventes por lo que no pudieron exhibirse todos los que había preparado. Que la llegada a última hora de la mayor parte del público creó una gran confusión en la puerta y en los despachos, razón por la que muchas personas entraron sin billete $\mathrm{y}$, por tanto, sin número para la rifa; $\mathrm{y}$ que, por el contrario, otros compraron su billete sin recibir el número». El crítico añade que si míster Velle hubiera colocado alrededor del tablado que había en el centro de la plaza algunos faroles grandes, el público habría podido apreciar los trabajos que allí se hicieron y no se hubiera quejado de la manera que lo hizo, en los puntos donde no veía. Concluye: «Por lo tanto, es difícil alumbrar bien locales tan inmensos, como la plaza de Toros de Badajoz. Hay que tener mucha previsión para que no sucedan cosas por el estilo de

${ }^{20}$ La Crónica, número 821, 8-VI-1875, p. [3].

21 La Crónica, número 1015, 18-II-1879, p. [3].

22 La Crónica, número 1026, 13-IV-1878, p. [3]. 
las acontecidas el domingo y que en una población menos sensata que la nuestra pudo ser causa de un gran conflicto» 23 .

\section{A MODO DE CONCLUSIÓN}

En los años que preceden a la inauguración del teatro López de Ayala, que ya hemos dicho supone un hito importante que marca el antes y el después de las actividades culturales y recreativas de la ciudad de Badajoz, y tomando como punto de partida las primeras noticias aparecidas en las páginas de la prensa local, con lo que ello permite de apoyo documental, podemos decir que se desarrollan en nuestra ciudad 213 espectáculos que perfectamente pueden encuadrarse en el concepto de parateatralidad del que hemos venido hablando a lo largo de este artículo. Dentro de esa cifra estarían incluidos los espectáculos musicales, concretamente 94 , que hemos dejado fuera de este estudio por cuanto ha sido nuestra intención insistir principalmente en el elemento festivo, con elevadas dosis de folclore (en el sentido popular que se aplica a esta expresión, destacando su carácter multitudinario e incluso de participación de las gentes en el propio espectáculo).

Hemos visto que los espectáculos parateatrales no musicales además de ser mayoría, son muy variados, aunque nosotros los hayamos agrupado para su estudio en cinco grupos. Desde manifestaciones ecuestres, pasando por espectros vivientes, cuadros disolventes, sombras impalpables, prestidigita-

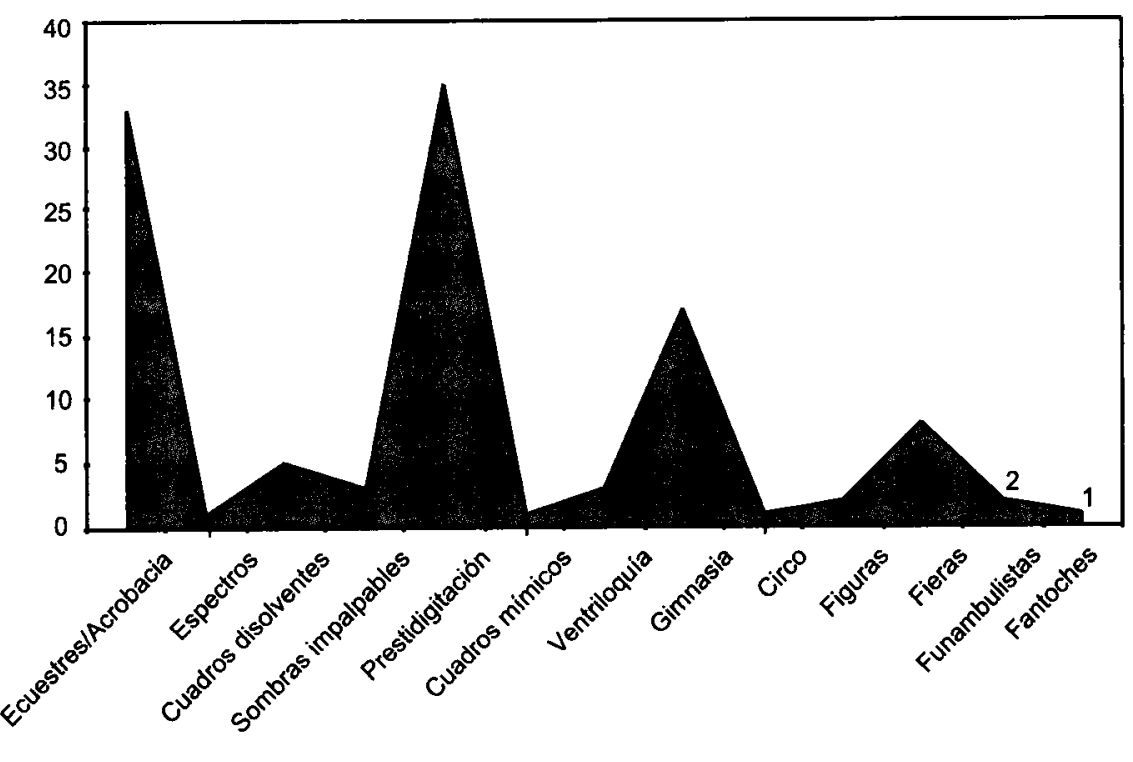

23 La Crónica, número 1114 (sic), 8-VII-1879, p. [3]. 
ción, cuadros mímicos, ventriloquía, gimnasia, acrobacia, fieras, funambulistas, hasta llegar a las figuras de ceras o eléctricas, constituyen el conjunto que hemos dado a conocer.

Como vemos, destacan las funciones de prestidigitación con 35 , lo que viene a suponer el $30 \%$ del total, o lo que es lo mismo, una de cada tres. A continuación se sitúan los ejercicios gimnásticos y acrobáticos, con caballos o sin ellos, con 33 funciones, representando otro tercio del total. El último tercio está constituido por espectáculos diversos.

Dos de cada tres funciones se celebraron en el periodo comprendido entre mayo y septiembre. Un total de 65 espectáculos parateatrales se desarrollaron en lo que podemos considerar época veraniega por estas latitudes.

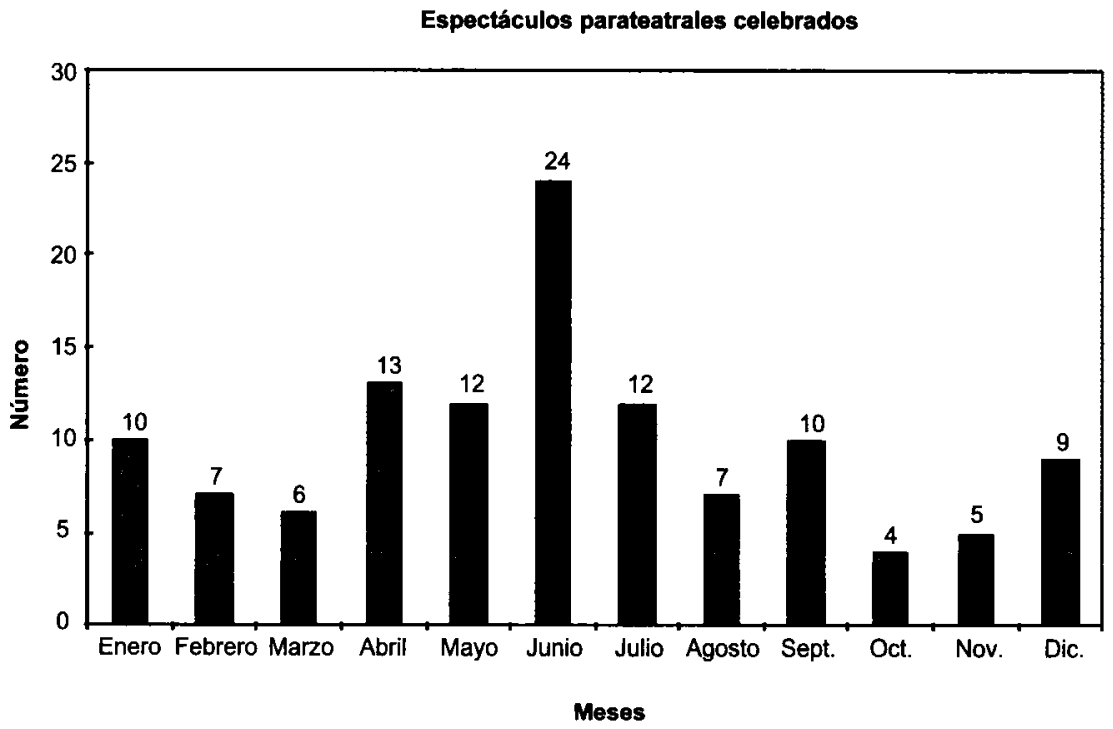

Aun así, dentro de ese periodo, se observa un descenso significativo en el mes de agosto que se convierte así en un mes flojo desde el punto de vista de los espectáculos, debido sin duda a la `huida de la ciudad de muchos de sus vecinos con motivo del excesivo calor, lo que disuadió a cualquier empresa para organizar funciones que resultaran rentables. En septiembre, no obstante, se reanudan con cierta intensidad las funciones, predisponiéndose así de alguna manera el ambiente para el inicio de la temporada teatral que solía dar comienzo a mediados de octubre. Como es comprensible, la celebración de espectáculos parateatrales solía hacerse en periodos en los que el teatro de la ciudad permanecía más tiempo cerrado. Queremos recordar brevemente que había dos periodos «fuertes» en la actividad teatral propiamente dicha: la temporada de invierno, entre octubre y enero; y la de primavera, tras el periodo de carnaval y hasta la Semana Santa. 
Como hemos podido observar, la media de representaciones aumenta a partir de 1874 , con notables descensos en 1877 y en el periodo comprendido entre 1881 y 1884 . Aun así, por encima de la media de los años anteriores, en los que se registran algunos totalmente en blanco $(1864,1866,1868$ y 1870), constituyéndose casi en excepciones los «picos» que representan 1867 y 1869.

Es evidente la relación de estos espectáculos con los propiamente teatrales, además de por los aspectos que mencionamos al inicio de este artículo, por el lugar en el que habitualmente solían celebrarse. Por último, hay que aclarar que en el apartado de «otros» hemos debido incluir aquellos espectáculos en los que no se especifica el lugar y los que tuvieron una ubicación especial: casas, locales de aficionados o la propia calle.

\section{RESUMEN}

Junto a un gran numero de representaciones teatrales llevadas a cabo por Compañías profesionales o por los grupos de aficionados que surgieron en cada localidad para canalizar el entusiasmo y el interés por el arte escénico que caracteriza, entre otras cosas, al teatro del siglo XIX, dotándolo de un sello de popularidad incuestionable, proliferaron los «otros» espectáculos, capaces de congregar multitudinariamente a las gentes. Estos espectáculos compartieron con los propiamente teatrales rasgos y características, aparte de celebrarse mayoritariamente en los Coliseos y Teatros. Con el tiempo llegaron a constituirse en espectáculos completamente independientes, recibiendo la denominación de parateatro, con la intención de remarcar algún aspecto diferenciador, y evolucionaron hacia fórmulas que hoy en día calificamos de circenses.

\section{Documento 1}

\section{SOLICITUD DE FIJAR EL PRECIO DE LA ENTRADA PARA FUNCIÓN DE PIROTECNIA TAURINA}

Habiendo concedido la correspondiente licencia a José Ignacio Cueto, profesor de Pirotegnica, para dar el día 8 del corriente en el Corralón de la Casa Hospicio, una función de su clase; lo comunico a Vs. para que se sirva fijarle el precio de entrada y adoptar las disposiciones que son consiguientes en casos de esta naturaleza.

Dios geue a Vsria. Badajoz 6 de Diciembre de 1845

Firma y rúbrica

Sor. Alcalde Const ${ }^{1}$. de esta Capital. 
ESPECTÁCULOS PARATEATRALES EN BADAJOZ EN EL SIGLO XIX (HASTA 1886)

Hoblimes concrite

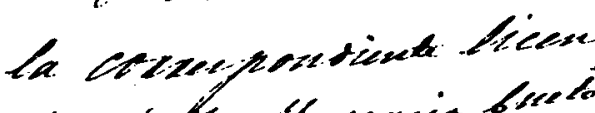

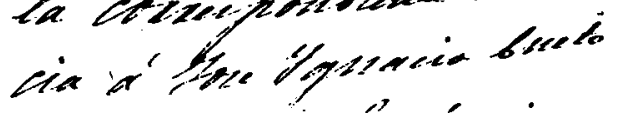

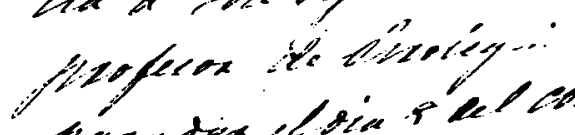

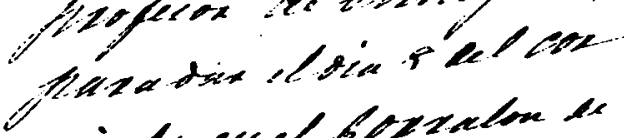

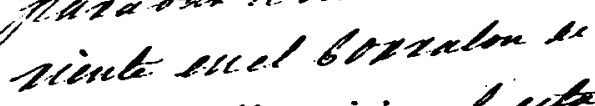

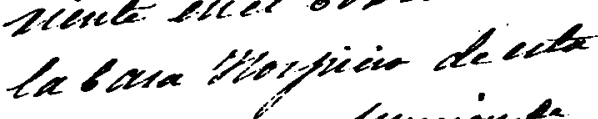

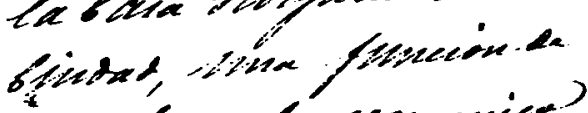

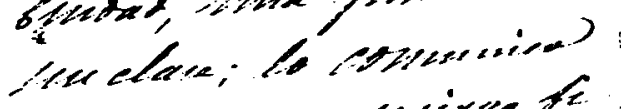

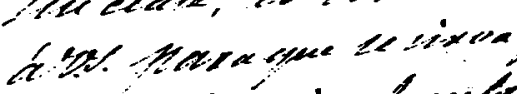

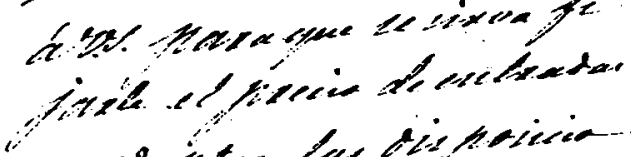

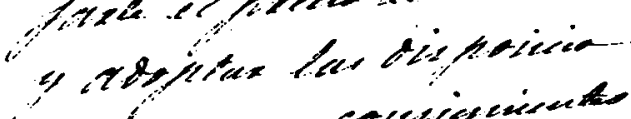

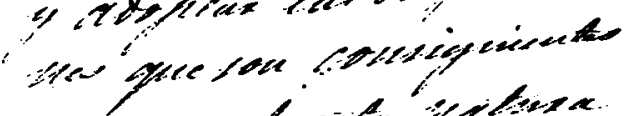

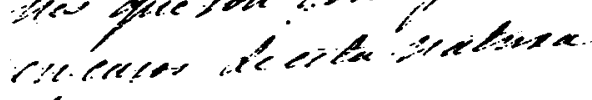
Lue

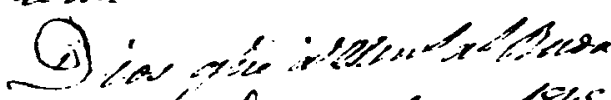

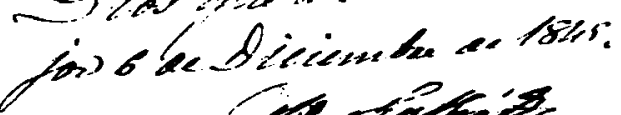

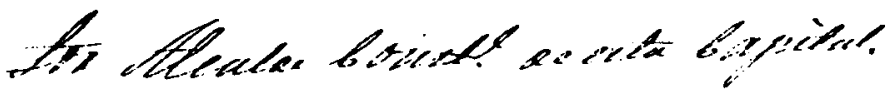

291 


\section{Documento 2}

\section{BORRADOR DETALLADO DE LA FUNCIÓN DE PIROTECNIA TAURINA}

Gran función de Tauromaquia y fuegos artificiales $q^{\mathrm{e}}$. se ha de ejecutar en la Plaza del corralon del hospicio el dia 8 del corriente (si el tiempo lo permite). Se lidiaran tres novillos para diversion de llos aficionados. Al primero se le pondrá una figurona que detonará con gran estrepito. En el segundo se presentará un figuron y al embertirle el toro arderá con preciosos fuegos. A el tercero se colocará en el centro de la plaza una figurilla conocida por Perico el chato, que girando sobre un eje figurará que le pone al toro un par de banderillas. Despues saldrá un soberbio toro (de pasta) y será picado por un moro montado en una jaquita artificial. En seguida se pasará a disparar el fuego por el orden siguiente. 1.․ La fuente del gran turco arrojando el fuego en distintas direcciones para imitar los surtidores de agua. 2. ${ }^{\circ}$ Combate de sol y Luna, en donde el fuego quedará apagado por espacio de dos segundos $\mathbf{p}^{\mathbf{a}}$. imitar un eclipse. 3. $\mathrm{E}$ El piramide de Egipto, con un salomonico iluminado. 4. ${ }^{\circ}$ El Molino de Dn. Quijote en donde el mismo fuego formará las alas de un Molino de viento con semicirculos iluminados. 5.- La gran Cruz de Malta: artificio de transformacion, que representará un Sol, despues la Cruz, y ultimamente una estrella de brillantes formados por el mismo fuego. 6. ${ }^{\mathrm{a}} \mathrm{Las}$ delicias del gran Sultan, adornado con preciosas flores distinguiendose un Tulipan, un girasol, y una guimalda de Jazmines. 7. ${ }^{\mathrm{a}}$ Un combate comuesto de cuatro baterias, arrojando los cañones alternativamente 140 balas blancas, cada una del tamaño de una manzana. 8. ․ El cabriolé de las damas. 9. auto (tachado) mata afilando una navaja sobre una piedra, y durante la accion de su trabajo tendrá un candil encendido. Ultima: La Diosa Vesta como Diosa del fuego estará colocada en medio de la plaza, al mismo tiempo una Sirena (tachado) situada Frente al Palco de Ayuntamiento al romper el fuego desplegará un victor que tendrá en sus manos quedandose toda la plaza iluminada y tan clara como si fueran las doce del dia, concluyendo con gran trueno en señal de haberse concluido el artificio. Principiará la función a las tres y media.

Precios

Entrada general .....

Palcos........

Asientos $1^{\text {os }}$. de barrera ......

Yd. $2^{\text {os }}$...

Gradillas ... 
Granfincion de Fauromaquia y fuegos artificiales q. Pe haide yjeciutar en la Plaza ded corralon del hospicioieldia 8 del corrienteffied tiempo to permite) Selidiavan Tres novillos para divession de bo aficionados. Aff primero pe le pontra una figurona gue deTonara con gran eitropito. En elfegundo fepresentara. en figuron yal embertivle el tiro arderá con svecioros Tregor. of el tercero de colocará en d centro de lajplata una figurilla conocida por Perico el chato, grectivin. do Pobre un gje figurara que le pone al toro cin par debanderillas. Sespues laldrá un loberbio horolde pas. 7a) y leva picado por un moro montado en cuna faquita

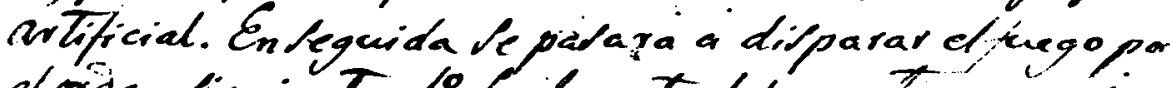
el criden tigeviente. lo Lafuente del gran Tuveo arrolaindo elfuego endirtintas direccioner paraimitar los furtionorep chaqua. 20 Combate de fol yduna, crotimbe el : :

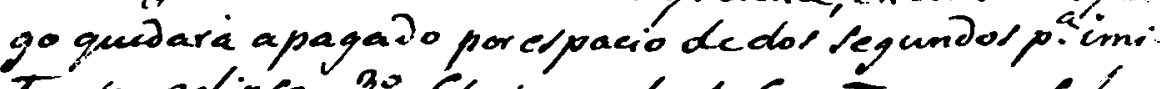
Tar un eclipse. 3: El piramide de Egipto, con consalomonico iluminado. 4'. El Clloline deD" "Fijote en donde el milmo fuego formava tas a las decun deolino de viento con temicircenlos iluminabos. S: dagran. Crun de cllalta i artificio de Trane for macion, que reprePentara un lol, despues la cruz, yultimainence ena estrella de brillantes formados por el mir mo fuego. 6.2ar deliciar del gran Sultan, adornato comprecioses tiores distinguiendose un Zulipan, ungivasol, y cema quivnalda de laz mines. Ya Un combate compunesto de "uatro baterias, arrojändo los cañoner alternativamer re: 150 balas blancas cadauna del tamaño derina manzana. qa el caliriolédelat damas. 99 lin art. 
ÁNGEl SuÁrez MuÑoz y SERGio SuÁrez Ramírez

tmata afilando una nabaja fdrecuna piedra, y durante la accion de ru tabajo tendra un candilencendido: Ultima: Ra Diora Herta como Diose del fue go estara. colocal a en misio de la plaza, al milmo tiempo una Sivena exasa frente al Palco de clyeentamiento al romper elfuego Jeplegara un vietor que tentraien fut manos quedandoke tida la plaza iluminaday Tan elara como if turean las Loce did diaponchyendo con ungran Friuems en leñal de hab expe conchides todo el artificio. Principiara la funcion a lar trosymed.

Precios

EnTrada general ...........

Palcop. - - - - . -

tficntos lodebarrera $\ldots \ldots$

Ya 2:\% - .

Gradillas...

294 


\section{Documento 3}

\section{DESCRIPCIÓN DE LA FUNCIÓN DE TEATRO DONDE SE EXHIBE EL NÚMERO PIRÁMIDES DEL EGIPTO}

\section{TEATRO}

Funcion estraordinaria para el miércoles 24 del corriente

Convencidos los Alcides de la indulgencia y proteccion con que hasta aquí le ha dispensado este generoso público, que por tantos títulos se hace acreedor á la mas alta gratitud, han dispuesto una funcion persuadidos de que no solo por haberla variado del modo mas posible, sino mas bien por su anhelo de complacer merecerá la aprobacion de tan bondadosos espectadores.

Despues de una brillante sinfonía se presentarán los referidos Alcides á desempeñar con su acostumbrada agilidad diferentes fuerzas de la mayor admiracion entre ellas las

Pirámides del Egipto,

en las que se formarán nuevors grupos todos movibles en su circunferencia orizontal. En seguida la Señora Emilia Amantí cantará el hermoso Rondó de la Opera la Pietra del Paragone. A su conclusion el Alcide Portuence subirá al Alambre flojo con la mayor destreza: en él ejecutará maravillosos y difíciles juegos, suertes, figuraciones y equilibrios que confia merecerán la atencion de tan indulgente público, distinguiéndose entre las muchas suertes con la graciosa escena de figurar encima de dicho alambre, el capeo y muerte de un toro al estilo andaluz, desempeñando al mismo tiempo con su capa y montera las mas jocosas y divertidas mudanzas y posturas propias del país.

En seguida el jóven Reis entre otros juegos y equilibrios desempeñará el sorprendente de la Pagoda china entre fuegos artificiales, suerte que en todas partes tiene llamado la mayor atencion; á lo que seguirán los mencionados Alcides á verificar estraordinarias fuerzas herculeas, particularizándose entre ellas con las nuevas del vuelo de los dos Arabes en la Mesa Romana; y el admirable giro de Hércules, Séfiro y Flora, y otras varias que serán de la mayor dificultad y nuevas en esta ciudad.

Dará principio a las ocho y media. 


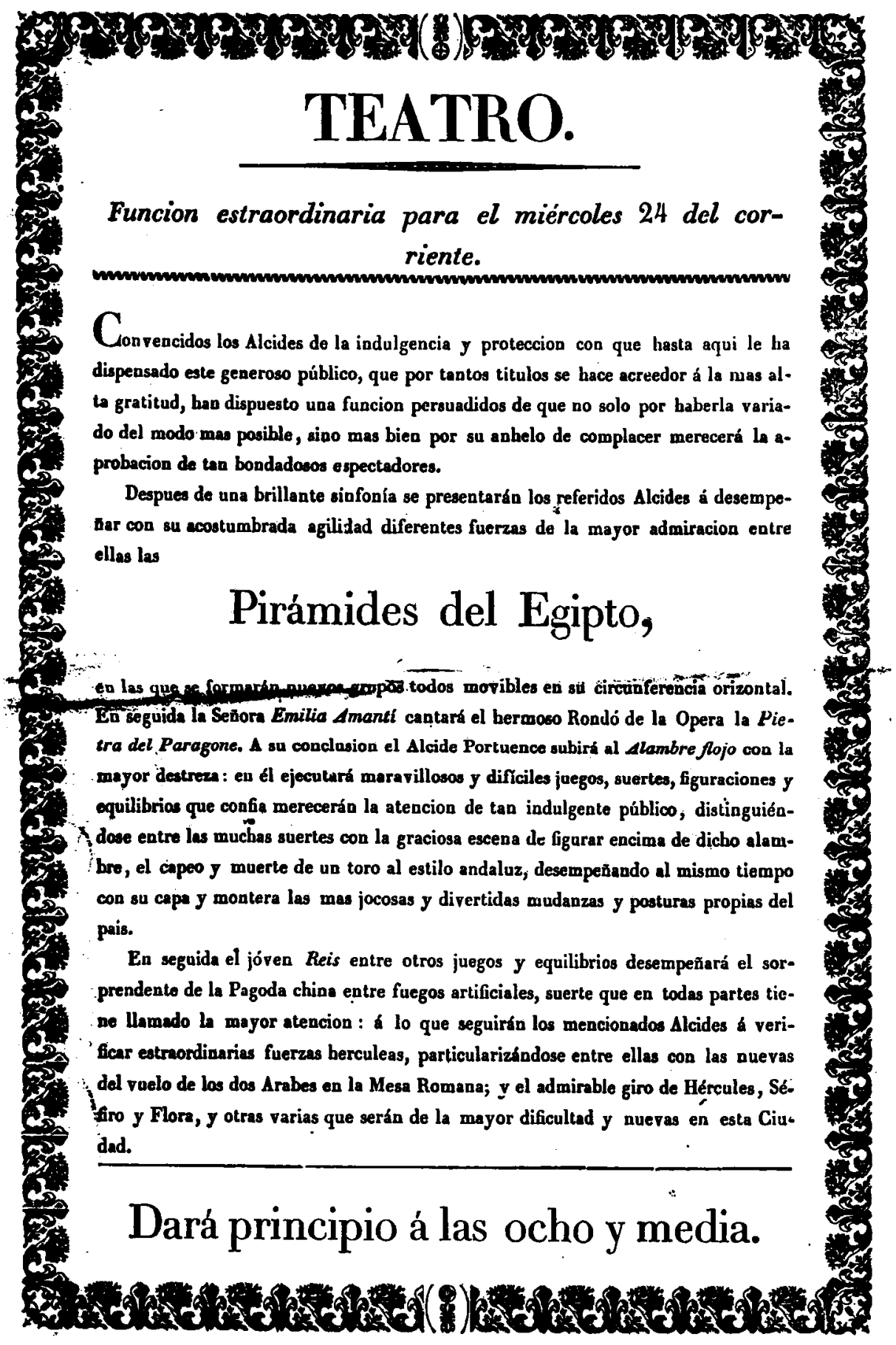

